\title{
Article \\ CesL Regulates Type III Secretion Substrate Specificity of the Enteropathogenic $E$. coli Injectisome
}

\author{
Miguel Díaz-Guerrero ${ }^{1}$, Meztlli O. Gaytán ${ }^{1}{ }^{(}$, , Eduardo Soto ${ }^{1,+}{ }^{\circledR}$, Norma Espinosa ${ }^{1}$, Elizabeth García-Gómez ${ }^{2}{ }^{\circledR}$, \\ Arely Marcos-Vilchis ${ }^{1}$, Angel Andrade ${ }^{3}(\mathbb{D})$ and Bertha González-Pedrajo ${ }^{1, *(D)}$ \\ 1 Departamento de Genética Molecular, Instituto de Fisiología Celular, Universidad Nacional Autónoma de \\ México, Ciudad de México 04510, Mexico; madiaz@ifc.unam.mx (M.D.-G.); \\ meztlli.gaytan@gmail.com (M.O.G.); jose.soto@yale.edu (E.S.); nespino@ifc.unam.mx (N.E.); \\ amarcos@ifc.unam.mx (A.M.-V.) \\ 2 Unidad de Investigación en Reproducción Humana, Consejo Nacional de Ciencia y Tecnología-Instituto \\ Nacional de Perinatología, Ciudad de México 11000, Mexico; egarciag@conacyt.mx \\ 3 Departamento de Microbiología, Facultad de Medicina, Universidad Autónoma de Nuevo León, Monterrey, \\ Nuevo León 64460, Mexico; angel.andradet@uanl.edu.mx \\ * Correspondence: bpedrajo@ifc.unam.mx; Tel.: +52-55-5622-5965; Fax: +52-55-5622-5611 \\ + Present address: Department of Microbial Pathogenesis, Yale University School of Medicine, \\ New Haven, CT 06536, USA.
}

\section{check for} updates

Citation: Díaz-Guerrero, M.; Gaytán, M.O.; Soto, E.; Espinosa, N.;

García-Gómez, E.; Marcos-Vilchis, A.; Andrade, A.; González-Pedrajo, B. CesL Regulates Type III Secretion Substrate Specificity of the Enteropathogenic E. coli Injectisome. Microorganisms 2021, 9, 1047. https:/ / doi.org/10.3390/microorganisms 905104

Academic Editor:

Francisco Ramos-Morales

Received: 29 March 2021

Accepted: 27 April 2021

Published: 13 May 2021

Publisher's Note: MDPI stays neutral with regard to jurisdictional claims in published maps and institutional affiliations.

Copyright: (C) 2021 by the authors. Licensee MDPI, Basel, Switzerland. This article is an open access article distributed under the terms and conditions of the Creative Commons Attribution (CC BY) license (https:/ / creativecommons.org/licenses/by/ $4.0 /)$.
Abstract: The type III secretion system (T3SS) is a complex molecular device used by several pathogenic bacteria to translocate effector proteins directly into eukaryotic host cells. One remarkable feature of the T3SS is its ability to secrete different categories of proteins in a hierarchical manner, to ensure proper assembly and timely delivery of effectors into target cells. In enteropathogenic Escherichia coli, the substrate specificity switch from translocator to effector secretion is regulated by a gatekeeper complex composed of SepL, SepD, and CesL proteins. Here, we report a characterization of the CesL protein using biochemical and genetic approaches. We investigated discrepancies in the phenotype among different cesL deletion mutants and showed that CesL is indeed essential for translocator secretion and to prevent premature effector secretion. We also demonstrated that CesL engages in pairwise interactions with both SepL and SepD. Furthermore, while association of SepL to the membrane does not depended on CesL, the absence of any of the proteins forming the heterotrimeric complex compromised the intracellular stability of each component. In addition, we found that CesL interacts with the cytoplasmic domains of the export gate components EscU and EscV. We propose a mechanism for substrate secretion regulation governed by the SepL/SepD/CesL complex.

Keywords: type III secretion system; EPEC; secretion hierarchy; CesL; gatekeeper complex

\section{Introduction}

Enteropathogenic Escherichia coli (EPEC) is a causal agent of human intestinal disease generating acute watery diarrhea in children [1]. EPEC belongs, together with enterohemorrhagic E. coli (EHEC), E. albertii and Citrobacter rodentium (CR), to a group of enteric pathogens (AE pathogens) able to induce an attaching and effacing histological lesion (AE lesion), characterized by the destruction of brush border microvilli, remarkable cytoskeletal alterations and intimate adherence of bacteria to the epithelial cell membrane [2-4]. A central element to EPEC pathogenicity is a type III secretion system (T3SS) or injectisome, which translocates effector proteins into the enterocyte cytosol $[5,6]$. The T3SS in AE pathogens is encoded on a chromosomal pathogenicity island known as locus of enterocyte effacement (LEE), which comprises 41 genes arranged into seven operons and four individual transcriptional entities [7-9]. Seven of the translocated effectors are encoded within the LEE, while the genes for around 16 others (named Nle, for non-LEE encoded effectors) are distributed elsewhere in the chromosome $[10,11]$. 
The T3SS is a supramolecular assemblage of about 20 different proteins organized into a multiring basal body that spans both membranes and the periplasm, a transmembrane export apparatus housed within the basal body at the inner membrane (IM), a set of cytosolic components, and an external conduit for secreted proteins [5,12]. Bacterial flagella are assembled by an evolutionarily related T3SS and several components of the flagellum share sequence and structural similarities to their injectisome counterparts $[13,14]$. In addition, it has recently been shown that the T3SS export apparatus also serves to assemble membranous surface structures called nanotubes, through which bacteria extract nutrients from the infected host cell [15].

In EPEC, the export apparatus is formed by the proteins EscR, EscS, EscT, EscU, and EscV (SctRSTUV in the unified T3SS nomenclature $[16,17]$ ) that together with the cytosolic ATPase complex formed by three proteins, EscN, EscL, EscO (SctNLO) and the sorting platform composed of EscQ, EscL and EscK (SctQLK), are crucial for secretion, having an important role in type III substrate docking and recognition as well as in energy fueling [5,18-21]. Moreover, based on what is known in other virulence T3S systems and in the flagellar T3SS (fT3SS), the core export apparatus proteins SctRST assemble as a helical structure above the IM, and the transmembrane domain of SctU wraps around this core while its C-terminal portion resides in the cytoplasmic side [22]. SctV is a polytopic IM protein with a large cytoplasmic C-terminal domain arranged as a toroidal nonameric ring, which is proposed to form an entry gate for T3 substrates [23-25].

T3 effectors travel through an extracellular continuous channel formed by a needle (a helical polymer of EscF subunits) a filament (a polymer of EspA subunits) and a translocation pore (formed by subunits of EspB and EspD proteins), which allows the passage of effector proteins through the host plasma cell membrane [26-29]. Multiple T3S substrates require the assistance of cognate chaperones for stabilization, to maintain a competent secretion conformation, for targeting to the export apparatus, to establish a secretion hierarchy and for proper translocation [30-32].

T3SS assembly and effector translocation are strictly regulated processes so that protein secretion is synchronized with the different stages of injectisome biogenesis. After the Sec-dependent assembly of the membrane rings and export apparatus, plus integration of the sorting platform and ATPase complex, type III mediated secretion initiates with the delivery of early substrates that form the inner rod and needle, followed by middle substrates or translocators, and lastly by late substrates or effectors [33,34]. The orderly secretion of these three different classes of proteins is achieved by two molecular switches that guarantee a precise secretion hierarchy.

The first substrate specificity switch, from early to middle substrates, is controlled by two proteins, EscU that belongs to the SctU family of proteins (YscU/SpaS/Spa40) and EscP of the SctP family (YscP/InvJ/Spa32). The ruler protein EscP is secreted until the needle reaches its final length, then, a productive interaction of EscP with the autocleaved form of EscU stops the secretion of early substrates and promotes, together with the second secretion switch, an efficient secretion of translocators $[35,36]$. The second molecular switch, from middle to late substrates, is regulated by proteins referred to as gatekeepers, SctW in the unified nomenclature (e.g., SepL, InvE, YopN-TyeA, SsaL, MxiC and PopN-Pcr1), and occurs once the translocon has been assembled and when the injectisome establishes contact with the eukaryotic cell [12]. Upon host cell contact, by means of an incompletely understood mechanism, an activation signal is transmitted through the needle-filament to the cytosolic components and the gatekeeper protein is either secreted/translocated, degraded, or dissociated from an acceptor site for effectors, thereby allowing the secretion of late substrates [37-47]. Indeed, it has been shown that some of the gatekeeper proteins regulate secretion substrate specificity by interacting with a component of the SctV protein family (EscV/SsaV/MxiA/PcrD), either altering its conformation to differentially recognize middle or late substrates or blocking a binding site for effectors [48-52]. Furthermore, many gatekeeper proteins promote the secretion of middle 
substrates, thus deletion mutants of the corresponding genes drastically diminished or abolished translocator secretion $[39,41,50,53,54]$.

In addition, some of the gatekeepers in different $\mathrm{T} 3 \mathrm{~S}$ systems function as complexes with proteins proposed to be acting as chaperones $[42,44,55,56]$. In the case of AE pathogens, the SepD protein forms a complex with SepL, and deletion mutants in both $\operatorname{sepD}$ and sepL exhibited an abolished secretion of translocators and hypersecretion of effectors, so the complex was proposed to control the secretion hierarchy between translocators and effectors $[36,54,57,58]$. Later, it was shown that the SepL-SepD complex associates with a third component, CesL, which was predicted to be a chaperone for SepL [59]. However, a direct interaction between these two proteins has not been proven and the function of CesL has not been extensively studied. It is also intriguing that distinct secretion phenotypes for cesL deletion mutants have been reported among AE pathogens $[48,54,60]$. Besides, SepL has been found to interact in a calcium-dependent manner with EscP, the molecular ruler of the first substrate specificity switch, in order to prevent premature effector secretion. The model proposes that once the translocation pore has been formed, a drop in calcium concentration disrupts the EscP-SepL interaction, enabling the secretion of late substrates [61]. The most recent mechanism reported for the functioning of the second molecular switch involves a SepD-SepL complex with the EscV export gate nonameric ring, rendering a high-affinity receptor for translocator-chaperone substrates and concurrently hindering the effector-chaperone access to the gate. Then, after the cell contact-dependent signal is transduced through the injectisome, SepD and SepL could dissociate from EscV to allow effector secretion [48].

In this work we aimed to characterize the role of CesL in the substrate secretion hierarchy within the heterotrimeric SepL/SepD/CesL complex. We propose a model that includes a functional interconnection between the two molecular switches for regulating translocator to effector secretion.

\section{Materials and Methods}

\subsection{Bacterial Strains and Growth Conditions}

Bacterial strains and plasmids used in this study are listed in Table 1. E. coli strains were aerobically grown at $37^{\circ} \mathrm{C}$ in Lysogeny Broth (LB) with constant shaking (250 rpm). When needed, bacterial cultures were supplemented with the appropriate antibiotics at the following concentrations: ampicillin, $100 \mu \mathrm{g} / \mathrm{mL}$; chloramphenicol, $25 \mu \mathrm{g} / \mathrm{mL}$; kanamycin, $50 \mu \mathrm{g} / \mathrm{mL}$; streptomycin, $50 \mu \mathrm{g} / \mathrm{mL}$; tetracycline, $20 \mu \mathrm{g} / \mathrm{mL}$.

Table 1. Strains and plasmids used in this study.

\begin{tabular}{|c|c|c|}
\hline Strain or Plasmid & Description $^{1}$ & Reference or Source \\
\hline \multicolumn{3}{|l|}{ E. coli } \\
\hline TOP10 & Strain used for cloning; $\mathrm{Sm}^{\mathrm{r}}$ & Invitrogen \\
\hline XL1-Blue & Strain used for plasmid propagation and DNA purification; $\mathrm{Tc}^{\mathrm{r}}$ & Stratagene \\
\hline BL21 (DE3) pLysS & Strain used for expression of pET19b based plasmids; $\mathrm{Cm}^{\mathrm{r}}$ & Novagen \\
\hline SU202 & Reporter strain for LexA-based two-hybrid assays; $\mathrm{Cm}^{\mathrm{r}} \mathrm{Km}^{\mathrm{r}}$ & [62] \\
\hline EPEC E2348/69 & Wild-type EPEC strain O127:H6; Sm ${ }^{\mathrm{r}}$ & [63] \\
\hline$\Delta e s c N$ & E2348/69 carrying an in-frame deletion of $e s c N ; \mathrm{Sm}^{\mathrm{r}}$ & [64] \\
\hline$\Delta c e s L$ & $\begin{array}{c}\text { E2348/69 cesL deletion mutant. Codons } 49 \text { to } 106 \text { were replaced } \\
\text { by the } a p h T \text { cassette; } \mathrm{Sm}^{\mathrm{r}} \mathrm{Km}^{\mathrm{r}}\end{array}$ & This study \\
\hline$\Delta c e s L_{2}:: \mathrm{km}$ & $\begin{array}{l}\text { E2348/69 cesL deletion mutant. Codons } 20 \text { to } 106 \text { were replaced } \\
\text { by the aphT cassette; } \mathrm{Sm}^{\mathrm{r}} \mathrm{Km}^{\mathrm{r}}\end{array}$ & This study \\
\hline$\Delta c e s L_{2}$ & $\begin{array}{l}\text { Derived from } \Delta c e s L_{2}:: \mathrm{km} \text {, the kanamycin cassette was removed; } \\
\mathrm{Sm}^{\mathrm{r}}\end{array}$ & This study \\
\hline$\Delta \operatorname{sep} D$ & E2348/69 carrying an in-frame deletion of $\operatorname{sep} D ; \mathrm{Sm}^{\mathrm{r}}$ & Gift of the Puente JL Lab \\
\hline$\Delta s e p L$ & E2348/69 carrying an in-frame deletion of sepL; Sm ${ }^{\mathrm{r}}$ & Gift of the Puente JL Lab \\
\hline$\Delta c e s L \Delta$ sepD & E2348/69 cesL and sepD double deletion mutant; $\mathrm{Sm}^{\mathrm{r}} \mathrm{Km}^{\mathrm{r}}$ & This study \\
\hline$\Delta c e s L \Delta \operatorname{sep} L$ & E2348/69 cesL and sepL double deletion mutant; $\mathrm{Sm}^{\mathrm{r}} \mathrm{Km}^{\mathrm{r}}$ & This study \\
\hline sepL-FLAG & E2348/69 expressing $3 \times$ FLAG-tagged SepL; Sm ${ }^{\mathrm{r}} \mathrm{Km}^{\mathrm{r}}$ & [49] \\
\hline
\end{tabular}


Table 1. Cont.

\begin{tabular}{|c|c|c|}
\hline Strain or Plasmid & Description $^{1}$ & Reference or Source \\
\hline sepL-FLAG $\Delta c e s L$ & $\begin{array}{c}\text { E2348/69 expressing } 3 \times \text { FLAG-tagged SepL and carrying a } \\
\text { deletion of } c e s L ; \mathrm{Sm}^{\mathrm{r}} \mathrm{Km}^{\mathrm{r}}\end{array}$ & This study \\
\hline sepL-FLAG $\Delta s e p D$ & $\begin{array}{c}\text { E2348/69 expressing } 3 \times \text { FLAG-tagged SepL and carrying an } \\
\text { in-frame deletion of sepD; } \mathrm{Sm}^{\mathrm{r}} \mathrm{Km}^{\mathrm{r}}\end{array}$ & This study \\
\hline cesL-FLAG & E2348/69 expressing $3 \times$ FLAG-tagged cesL; $\mathrm{Sm}^{\mathrm{r}} \mathrm{Km}^{\mathrm{r}}$ & This study \\
\hline cesL-FLAG $\Delta s e p L$ & $\begin{array}{c}\text { E2348/69 expressing } 3 \times \text { FLAG-tagged CesL and carrying an } \\
\text { in-frame deletion of sepL; } \mathrm{Sm}^{\mathrm{r}} \mathrm{Km}^{\mathrm{r}}\end{array}$ & This study \\
\hline cesL-FLAG $\Delta s e p D$ & $\begin{array}{c}\text { E2348/69 expressing } 3 \times \text { FLAG-tagged CesL and carrying an } \\
\text { in-frame deletion of sepD; } \mathrm{Sm}^{\mathrm{r}} \mathrm{Km}^{\mathrm{r}}\end{array}$ & This study \\
\hline \multicolumn{3}{|c|}{ 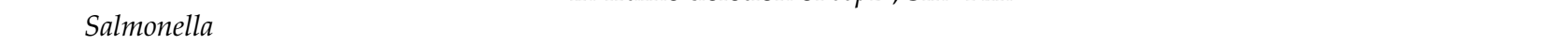 } \\
\hline SJW1368 & $\begin{array}{l}\text { Strain used for expression of pTrc99A-based plasmids; flagellar } \\
\text { master operon mutant, } \Delta(\text { cheW-flhD })\end{array}$ & [65] \\
\hline JR501 & $\begin{array}{l}\text { Strain used to convert E. coli derived plasmids to Salmonella } \\
\text { compatibility }\end{array}$ & [66] \\
\hline \multicolumn{3}{|l|}{ Saccharomyces cerevisiae } \\
\hline PJ69-4a/ $\alpha$ & 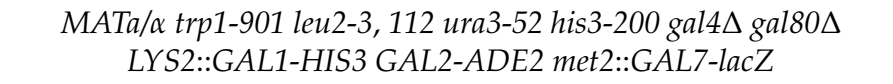 & {$[67]$} \\
\hline pKD4 & $\begin{array}{l}\text { Template plasmid for amplification of the kanamycin resistance } \\
\text { cassette }\end{array}$ & [68] \\
\hline pKD46 & $\begin{array}{c}\lambda \text {-Red recombinase system plasmid with an inducible } a r a B \\
\text { promoter; } \mathrm{Ap}^{\mathrm{r}}\end{array}$ & [68] \\
\hline pSUB11 & $\begin{array}{l}\text { Template plasmid for amplification of the } 3 x-F L A G \text { epitope and } \\
\text { kanamycin resistant cassette; } \mathrm{Ap}^{\mathrm{r}} \mathrm{Km}^{\mathrm{r}}\end{array}$ & [69] \\
\hline pFLP2 & Plasmid used for expression of the Flp recombinase; $\mathrm{Ap}^{\mathrm{r}}$ & [70] \\
\hline pTrc99A & Expression vector with an inducible trc promoter; $\mathrm{Ap}^{\mathrm{r}}$ & Amersham-Pharmacia \\
\hline pTrc99A_FF4 & $\begin{array}{c}\text { Modified pTrc99A expression vector with an inducible trc } \\
\text { promoter; } \mathrm{Ap}^{\mathrm{r}}\end{array}$ & {$[71]$} \\
\hline pMTcL & cesL cloned into pTrc99A_FF4 (NdeI- BamHI) & This study \\
\hline pMTHcL & his-cesL cloned into pTrc99A (NcoI-BamHI) & This study \\
\hline pATpD & sepD cloned into pTrc99A_FF4 & [49] \\
\hline pMTpL & sepL gene cloned into pTrc99A_FF4 & [49] \\
\hline pMTBISpDcL & sepD and his-cesL cloned into pTrc99A_FF4 & [49] \\
\hline pMTBISpDpL & sepD and his-sepL cloned into pTrc99A_FF4 & This study \\
\hline pMTBISpLcL & sepL and his-cesL cloned into pTrc99A_FF4 & This study \\
\hline pMTBISpLpD & sepL and his-sepD cloned into pTrc99A_FF4 & This study \\
\hline $\mathrm{pMTBISpDpL}_{\Delta 75}$ & $\begin{array}{l}\text { sepD and his-sepL lacking codons } 1 \text { to } 225 \text { cloned into } \\
\text { pTrc99A_FF4 }\end{array}$ & This study \\
\hline pET19b & $\begin{array}{c}\text { Plasmid used for expression of His tagged proteins under the } \\
\text { control of an inducible T7 promoter, } \mathrm{Ap}^{\mathrm{r}}\end{array}$ & Novagen \\
\hline pAEpD & sepD cloned into pET19b (NdeI-BamHI) & This study \\
\hline pMEcL & cesL cloned into $\mathrm{pET} 19 \mathrm{~b}$ & [49] \\
\hline pMEpL & sepL cloned into pET19b (NdeI-BamHI) & This study \\
\hline $\mathrm{pMEpL}_{\Delta 75}$ & sepL lacking codons 1 to 225 cloned into pET19b (NdeI-BamHI) & This study \\
\hline $\mathrm{pMEpL}_{\Delta 81-94}$ & $\begin{array}{c}\text { sepL lacking codons } 240 \text { to } 282 \text { cloned into pET19b (NdeI and } \\
\text { BamHI) }\end{array}$ & This study \\
\hline $\mathrm{pKEeD}_{\mathrm{N}}$ & esc $D$ codons 1 to 120 cloned into $\mathrm{pET} 19 \mathrm{~b}$ & [49] \\
\hline $\mathrm{pKEeV}_{\mathrm{C}}$ & esc $V$ codons 335 to 675 cloned into pET19b & [49] \\
\hline $\mathrm{pJEeU}_{\mathrm{C}}$ & escl codons 215 to 345 cloned into pET19b & [35] \\
\hline pACTrc & $\begin{array}{c}\text { pACYC184 expression vector derivative; } \mathrm{pTrc} \text { promoter, p15A } \\
\text { origin of replication, lacIq; } \mathrm{Cm}^{\mathrm{r}}\end{array}$ & [72] \\
\hline pMATpD & sepD gene cloned into pACTrc (NdeI-BamHI) & This study \\
\hline pMATpL & sepL gene cloned into pACTrc & [49] \\
\hline $\operatorname{pMATpL}_{\Delta 30}$ & sepL lacking codons 1 to 90 cloned into pACTrc (NdeI-BamHI) & This study \\
\hline $\operatorname{pMATpL}_{\Delta 81-94}$ & $\begin{array}{l}\text { sepL lacking codons } 240 \text { to } 282 \text { cloned into pACTrc } \\
\text { (NdeI-BamHI) }\end{array}$ & This study \\
\hline pMATcL & cesL cloned into pACTrc (NdeI- BamHI) & This study \\
\hline pMATcL2HA & cesL-2HA cloned into pACTrc (HindIII-BamHI) & This study \\
\hline $\mathrm{pMATcL}_{\mathrm{C} \Delta 10}$ & cesL lacking codons 107-117 cloned into pACTrc (NdeI-BamHI) & This study \\
\hline
\end{tabular}


Table 1. Cont.

\begin{tabular}{|c|c|c|}
\hline Strain or Plasmid & Description $^{1}$ & Reference or Source \\
\hline pMAL-c2X & $\begin{array}{l}\text { Plasmid used for expression of MBP-tagged proteins under the } \\
\text { control of the tac promoter; } \mathrm{Ap}^{\mathrm{r}}\end{array}$ & New England Biolabs \\
\hline pMLcL & cesL gene cloned into pMAL-c2X (BamHI-HindIII) & This study \\
\hline $\mathrm{pMLcL}_{\mathrm{C} \Delta 10}$ & $\begin{array}{c}\text { cesL lacking codons } 107-117 \text { cloned into pMAL-c2X } \\
\text { (BamHI-PstI) }\end{array}$ & This study \\
\hline pТOPO-2HA & $\begin{array}{l}\text { pCR2.1-TOPO derivative carrying C. rodentium espG } \\
\text { (HindIII-XhoI) tagged with 2-HA epitopes; } \mathrm{Km}^{\mathrm{r}} \mathrm{Ap}^{\mathrm{r}}\end{array}$ & {$[36]$} \\
\hline pMHcL & ces $L$ with its native RBS cloned into pTOPO-2HA (HindIII-XhoI) & This study \\
\hline $\mathrm{pJHeH}$ & $\begin{array}{c}\text { espH with its native RBS cloned into pTOPO-2HA } \\
\text { (HindIII-XhoI) }\end{array}$ & [35] \\
\hline pGBKT7 & $\begin{array}{c}\mathrm{Y} 2 \mathrm{H} \text { vector containing GAL4 DNA binding domain; TRP1 } \\
\text { nutritional marker }\end{array}$ & Clontech \\
\hline pOGBpD & sepD gene cloned into pGBKT7 (NdeI-BamHI) & This study \\
\hline pGBKT7-53 & $\begin{array}{l}\text { pGBKT7 encoding a fusion of the GAL4 DNA binding domain } \\
\text { with murine p53 }\end{array}$ & Clontech \\
\hline pGBKT7-Lam & $\begin{array}{l}\text { pGBKT7 encoding a fusion of the GAL4 DNA binding domain } \\
\text { with human lamin C }\end{array}$ & Clontech \\
\hline pGADT7 & $\begin{array}{c}\text { Y2H vector containing GAL4 activation domain; LEU2 } \\
\text { nutritional marker }\end{array}$ & Clontech \\
\hline pMGADpL & sepL cloned into pGADT7 (NdeI-BamHI) & This study \\
\hline $\operatorname{pOGADpL}_{\Delta 81-94}$ & sepL lacking codons 81-94 cloned into pGADT7 (NdeI-BamHI) & This study \\
\hline pMGADcL & cesL gene cloned into pGADT7 (NdeI-BamHI) & This study \\
\hline pMGADcL $_{\mathrm{C} \Delta 10}$ & cesL lacking codons 107-117 cloned into pGADT7 (NdeI-BamHI) & This study \\
\hline pGADT7-T & $\begin{array}{l}\text { pGADT7 encoding a fusion of the GAL4 activation domain } \\
\text { with the simian virus } 40 \text { (SV40) large T antigen }\end{array}$ & Clontech \\
\hline pSR658 & $\begin{array}{l}\text { Encodes LexA DNA binding domain (WT). ColE1 origin of } \\
\text { replication; } \mathrm{Tc}^{\mathrm{r}}\end{array}$ & Gift of the Puente JL Lab \\
\hline pMR58cL & cesL cloned into pSR658 (XhoI-KpnI) & This study \\
\hline pMR58pD & sepD cloned into pSR658 (XhoI-KpnI) & This study \\
\hline pMR58tir & tir cloned into pSR658 (XhoI-KpnI) & This study \\
\hline pSR659 & $\begin{array}{l}\text { Encodes LexA DNA binding domain (Mut). p15A origin of } \\
\text { replication; } \mathrm{Ap}^{\mathrm{r}}\end{array}$ & Gift of the Puente JL Lab \\
\hline pMR59cT & cesT cloned into pSR659 (KpnI-BamHI) & This study \\
\hline pMR59pD & sepD cloned into pSR659 (XhoI-KpnI) & This study \\
\hline pMR59pL & sepL cloned into pSR659 (BamHI-XhoI) & This study \\
\hline
\end{tabular}

${ }^{1}$ Sm: streptomycin; Km: kanamycin; Cm: chloramphenicol; Tc: tetracycline.

\subsection{Construction of EPEC Null Mutants and Tagged Strains}

The oligonucleotides used in this study are listed in Table 2. The non-polar mutant of cesL $(\Delta c e s L)$ was constructed using the $\lambda$-Red recombination system [68]. Briefly, the kanamycin resistance cassette was amplified from plasmid pKD4 using primers delcesLSRS_Fw and delcesL_Rv (Table 2). The resulting PCR product was electroporated into EPEC wild-type (WT), $\Delta$ sepD or $\Delta s e p L$ strains carrying plasmid pKD46. For the $C$. rodentium deletion mutant $\left(\Delta c e s L_{2}:: \mathrm{km}\right)$ the kanamycin resistance cassette was amplified from pKD4 using primers delcesL_Fw and delcesL_Rv. Deletion mutants were selected on LB plates containing kanamycin at $37^{\circ} \mathrm{C}$. The kanamycin cassette was excised from the chromosome of the $\Delta c e s L_{2}:: \mathrm{km}$ mutant using the FLP recombinase encoded in the pFLP2 plasmid [70]. To generate the sepL-FLAG $\triangle c e s L$ strain, the kanamycin cassette from the sepL-FLAG strain was excised and the cesL deletion was obtained as mentioned above. Chromosomal epitope tagging was performed as previously described [69]. The EPEC strains expressing a $3 \times$ FLAG-tagged version of sepL (sepL-FLAG), or a $3 \times$ FLAG-tagged version of cesL (cesL-FLAG), were constructed with the $\lambda$-Red recombination strategy using plasmid pSUB11 as a template for amplification of the $3 \times$ FLAG-kanamycin cassette [69]. The primers used to tag sepL and cesL on the chromosome were sepL-3FLAG_Fw/sepL3FLAG_Rv and cesL-3FLAG_Fw/cesL-3FLAG_Rv, respectively. All genetic modifications 
were verified by PCR. Proper expression of the FLAG-tagged proteins was confirmed by immunoblotting.

Table 2. Oligonucleotides used in this study.

\begin{tabular}{|c|c|}
\hline Oligonucleotide & Sequence $5^{\prime}$ to $3^{\prime}$ \\
\hline delcesLSRS_Fw & AACCGTGTTGAAATTGATTTTAATGGGTTTTCTTTTTTTATTGAAATAATTGATAATAATGTGTAGGCTGGAGCTGCTTCGAAGTTCCTATA \\
\hline delcesL_Rv & ATTTAAGAGTTTATTCATGATGTCATCCTGCGAACGCGCTCAATAATCTGAATATCCTCCTTAGTTCCTA \\
\hline delcesL_Fw & TTTTAGTTAAAAGAAATGTTGAAGAGTTTTTAAGATTGTTGGGAAATGATGTGTAGGCTGGAGCTGCTTC \\
\hline sepL-3FLAG_Fw & ATACATTATTAATGATTGGTAAAGTGATAGATTATAAGGAGGATGTTATGGACTACAAAGACCATGACGG \\
\hline sepL-3FLAG_Rv & 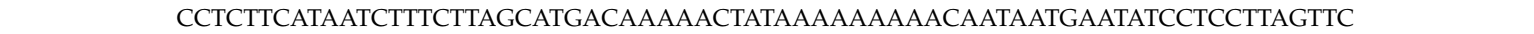 \\
\hline cesL-3FLAG_Fw & GAATACTTTTCAACAGCATGTGCAGATTATTGAGCGCGTTCGCAGGATGACATCAGACTACAAAGACCATGACGG \\
\hline cesL-3FLAG_Rv & AAGATCGTGATATGACTCTGCTTTTTTAAATATATTTAAGAGTTTATTCATATGAATATCCTCCTTAGTTC \\
\hline sepLNdeI_Fw & AGTTTCATATGGCTAATGGTATTG \\
\hline sepLNdeI $\Delta 30 \_$Fw & GCAATTACATATGCAAAAAAATTC \\
\hline sepLNde $\Delta 75 \_F w$ & GAATTTAATCATATGCCCGCATCT \\
\hline sepLBamHI_Rv & CTATAAAAAAAAGGATCCTCACAT \\
\hline sepL $\Delta 81-94-\bar{A} \_$Rv & ACCGATAGTGATAAAATAAAAGAA \\
\hline sepL $\Delta 81-94-B \_F w$ & ATCACTATCGGTTGTCGTGCCTTC \\
\hline cesLBamHI_Fw & AGCCTGGGATCCAATCTTTTAGT \\
\hline cesLHindIII_Rv & ATTTAAAAGCTTATTCATGATGTC \\
\hline cesLMalPstI_Rv & ACGCGCTGCAGTTACTGCACATGC \\
\hline cesLNdeI_Fw & AGAGCCTGCATATGAATCTTTTAG \\
\hline cesLC $\Delta 10 \_$Rv & GGATCCTCACTGCACATGCTGTTG \\
\hline cesLHA_Fw & TACTGTAAGCTTTATCCAATACGC \\
\hline cesLHA_Rv & TTAAGAGTTCTCGAGTGATGTCAT \\
\hline sepDXhoI_Fw & ACGGGTACTCGAGATGAACAATA \\
\hline sepDKpn_Rv & ACTTATTGGTACCATTACACAATTC \\
\hline tirXhol_Fw & AAAGGATCTCGAGATGCCTATTGG \\
\hline tirKpn_Rv & CTCACAGGTACCTTTAAACGAAAC \\
\hline cesLXhoI_Fw & CAGAGCCTCGAGATGAATCTTTTA \\
\hline cesLKpnI_Rv & ATTTAAGGGTACCTTCATGATGTC \\
\hline sepLBamHIFw & ATTACGTGAGGATCCATGGCTAAT \\
\hline sepLXhoIstop_Rv & AAAACTCGAGATCACATAACATCC \\
\hline cesTBamHI_Fw & AAGAGAAGGATCCATGTCATCAAG \\
\hline cesTKpnI_Rv & CTAATAAGGTACCTTTATCTTCCG \\
\hline
\end{tabular}

\subsection{Plasmid Construction}

Restriction enzymes, Q5 DNA Polymerase and T4 DNA ligase were obtained from New England Biolabs and used according to the manufacturer's instructions. PCR reactions were performed using EPEC genomic DNA as template and the indicated primers. All plasmids used in this work are listed in Table 1. Plasmids pMEpL and pMGADpL were generated by subcloning sepL from pMTpL, into the NdeI/BamHI restriction sites of the pET19b and pGADT7 vectors, respectively. Plasmids pAEpD, pMATpD and pOGBpD, were constructed by subcloning sepD from pATpD, into the NdeI/BamHI sites of the pET19b, pACTrc and pGBKT7 vectors, respectively. Plasmids pMTcL, pMATcL and pMGADcL, were made by subcloning cesL from pMEcL, into the NdeI/BamHI sites of pTrc99A_FF4, pACTrc and pGADT7 vectors, respectively. Plasmid pMTHcL was generated by subcloning his-cesL from pMEcL, into the NcoI/BamHI sites of pTrc99A vector.

PCR amplification of sepL truncated versions sep $L_{\Delta 30}$ and $\operatorname{sep} L_{\Delta 75}$, was achieved using the primer pairs sepLNdeI $\Delta 30 \_F w / \operatorname{sepLBamHIRv}$ and $\operatorname{sepLNdeI} \Delta 75 \_F w / \operatorname{sepLBamHI} R$ v, respectively. A sepL in-frame deletion lacking codons 240 to 282 (sepL $\left.L_{\Delta 81-94}\right)$ was constructed by overlapping PCR. The first round of PCR was performed with primer pairs sepLNdeI_Fw /sepL $\Delta 81-94-A \_R v$ and sepL $\Delta 81-94-B \_F w / s e p L B a m H I \_R v$, and the resulting amplicons were purified and used as template for a second round of PCR using the primer pair sepLNdeI_Fw/sepLBamHI_Rv. Purified amplicons sepL $L_{\Delta 30}$, sepL $L_{\Delta 75}$ and sepL $L_{\Delta 81-94}$ were cloned into the NdeI/BamHI sites of pTrc99A_FF4 or pET19b plasmids to generate $\mathrm{pMATpL}_{\Delta 30}, \mathrm{pMEpL}_{\Delta 75}$, and $\mathrm{pMEpL}_{\Delta 81-94}$, respectively. Plasmids pMATpL $\mathrm{M}_{\Delta 1-94}$ and pOGADpL ${ }_{\Delta 81-94}$ were generated by subcloning sep $L_{\Delta 81-94}$ from $p M E p L_{\Delta 81-94}$ into the NdeI/BamHI sites of pACTrc and pGADT7, respectively.

To generate bicistronic constructs, plasmids pMEcL, pAEpD, pMEpL or pMEpL ${ }_{\Delta 75}$, were digested with $\mathrm{XbaI} /$ PstI restriction enzymes. The resulting products his-cesL, his-sepD, his-sepL, and his-sep $L_{\Delta 75}$ were subcloned into the XbaI/PstI sites of pMTpL or pATpD, yielding plasmids pMTBISpLcL, pMTBISpLpD, pMTBISpDpL and $\mathrm{pMTBISpDpL}_{\Delta 75}$, respectively. 
Plasmids encoding $\operatorname{ces} L_{\mathrm{C} \Delta 10}$ (lacking codons 107-117), were constructed by PCR using the primer pair cesLNdeI_Fw/cesL $\mathrm{C}_{\mathrm{C} 10 \_} \mathrm{Rv}$. The resulting amplicon was cloned into the NdeI/BamHI sites of pACTrc or pGADT7 plasmids to generate pMATcL $\mathrm{C}_{\mathrm{C} 10}$ and $\mathrm{pMGADcL}_{\mathrm{C} \triangle 10}$, respectively. To construct CesL N-terminal MBP-tagged versions, full-length cesL or cesL $L_{C} \Delta 10$ were amplified by PCR with primer pairs cesLBamHI_Fw/cesLHindIII_Rv and cesLBamHI_Fw/cesLMALPstI_Rv, respectively. Purified amplicons were cloned into the BamHI/HindIII or BamHI/PstI sites of pMAL-c2X plasmid to generate pMLcL and pMLcL ${ }_{\mathrm{C} \Delta 10}$, respectively. The C-terminal 2HA-tagged version of CesL (CesL-HA) was generated by PCR amplification of the cesL coding region including its native ribosome-binding site with the primer pair cesLHA_Fw/cesLHA_Rv. The purified amplicon was cloned into the HindIII/XhoI sites of pTOPO-2HA plasmid to generate pMHcL. Plasmid pMATcL2HA was constructed by subcloning cesL-2HA from pMHcL into the HindIII/BamHI sites of the pACTrc vector.

To create the bacterial two-hybrid constructs, the coding regions of $\operatorname{sep} D$, tir, and cesL were amplified by PCR using the primer pairs sepDXhoI_Fw/sepDKpn_Rv, tirXhoI_Fw/tirKpn_Rv and cesLXhoI_Fw/cesLKpnI_Rv, respectively. The purified amplicons were cloned into the $\mathrm{XhoI} / \mathrm{KpnI}$ sites of pSR658 vector, to create $\mathrm{pMR} 58 \mathrm{pD}$, pMR58tir and pMR58cL, respectively. Additionally, sepL and cesT were amplified by PCR with the primer pairs sepLBamHI_Fw/sepLXhoIstop_Rv and cesTBamHI_Fw/cesTKpnI_Rv, respectively. Purified amplicons were cloned into the BamHI/KpnI sites of pSR659 vector to create $\mathrm{pMR} 59 \mathrm{pL}$ and $\mathrm{pMR} 59 \mathrm{cT}$, respectively. Plasmid $\mathrm{pMR} 59 \mathrm{pD}$ was generated by subcloning sepD from $\mathrm{pMR} 58 \mathrm{pD}$ into the $\mathrm{XhoI} / \mathrm{KpnI}$ sites of pSR69 vector.

All constructs resulting from PCR amplification were verified by DNA sequencing at the Instituto de Fisiología Celular, UNAM.

\subsection{Protein Solubility Assay}

Plasmids transferred from E. coli into Salmonella SJW1368 were first transformed into Salmonella JR501, which is a restriction-deficient modification-proficient strain [73]. Salmonella SJW1368 harboring plasmids pMTBISpDcL, pMTBISpLcL or pMTBISpDcL, in addition to plasmid pMATpL, was grown at $37^{\circ} \mathrm{C}$ until an $\mathrm{OD}_{600}$ of $0.6-0.8$ was reached. Protein expression was induced with $0.1 \mathrm{mM}$ isopropyl- $\beta$-D-thiogalactopyranoside (IPTG) for $4 \mathrm{~h}$ at $30^{\circ} \mathrm{C}$. Cell cultures were harvested by centrifugation at $8000 \times \mathrm{g}$ for $10 \mathrm{~min}$. The harvested cells were resuspended in $10 \mathrm{~mL}$ of buffer $(20 \mathrm{mM}$ Tris- $\mathrm{HCl} \mathrm{pH} \mathrm{7.4,500} \mathrm{mM}$ $\mathrm{NaCl}$ ), lysed by sonication and centrifuged at $27,000 \times g$ for $30 \mathrm{~min}$ at $4{ }^{\circ} \mathrm{C}$ to separate the soluble and insoluble fractions. The insoluble fraction (pellet) was resuspended in the same buffer and volume as that used for the soluble fraction. Buffer $1 \times$ SDS-PAGE was added to protein samples from both fractions, normalized according to the $\mathrm{OD}_{600}$ of the respective bacterial culture.

\subsection{Purification of Trimeric Complexes}

Salmonella SJW1368 cells co-transformed with plasmids pMTBISpDpL and pMATcL, pMTBISpLpD and pMATcL, pMTBISpDcL and pMATpL, pMTBISpDcL and $\mathrm{pMATpL}_{\Delta 30}$ or pMTBISpDpL $\mathrm{L}_{\Delta 5}$ and pMATcL were grown in $200 \mathrm{~mL}$ of $\mathrm{LB}$ to an $\mathrm{OD}_{600}$ of $0.6-0.8$. At this point, protein production was induced by addition of $0.1 \mathrm{mM}$ IPTG and bacterial growth was continued for $4 \mathrm{~h}$ at $30^{\circ} \mathrm{C}$. Cells were collected by centrifugation at $8000 \times g$ for $10 \mathrm{~min}$ and resuspended in $10 \mathrm{~mL}$ of lysis buffer $(20 \mathrm{mM}$ Tris- $\mathrm{HCl} \mathrm{pH} \mathrm{7.4,500} \mathrm{mM} \mathrm{NaCl}, 10 \mathrm{mM}$ imidazole) supplemented with $1 \mathrm{mM}$ phenylmethylsulfonyl fluoride (PMSF). Cells were lysed by sonication and then centrifuged at $27,000 \times g$ for $30 \mathrm{~min}$ at $4{ }^{\circ} \mathrm{C}$. The cleared cell lysate was loaded onto a column containing $200 \mu \mathrm{L}$ of Ni-NTA agarose beads (Qiagen). Coupled agarose beads were washed three times with $10 \mathrm{~mL}$ of lysis buffer with increasing concentrations of imidazole $(10 \mathrm{mM}, 30 \mathrm{mM}$ and $60 \mathrm{mM})$. Finally, bound proteins were eluted with three column volumes of lysis buffer containing $400 \mathrm{mM}$ imidazole. 


\subsection{Pull-Down Assays}

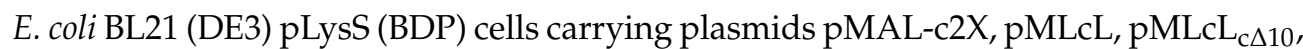
$\mathrm{pATpD}, \mathrm{pMTpL}, \mathrm{pKEeV}_{\mathrm{C}}, \mathrm{pJEeU}_{\mathrm{C}}$ or $\mathrm{pKEeD}_{\mathrm{N}}$ were cultured in $100 \mathrm{~mL}$ of $\mathrm{LB}$ supplemented with $0.1 \%$ glucose at $37^{\circ} \mathrm{C}$ until an $\mathrm{OD}_{600}$ of $0.6-0.8$ was reached. Then, IPTG was added to a final concentration of $0.3 \mathrm{mM}$ for pMAL-c2X-based constructions or $0.1 \mathrm{mM}$ for pTrc99A_FF4- and pET19b-based constructions, and growth was continued for $4 \mathrm{~h}$ at $30^{\circ} \mathrm{C}$. Cells were collected by centrifugation at $8000 \times \mathrm{g}$ for $10 \mathrm{~min}$, resuspended in $10 \mathrm{~mL}$ of lysis buffer (50 mM Tris- $\mathrm{HCl} \mathrm{pH} 7.4,200 \mathrm{mM} \mathrm{NaCl}, 1 \mathrm{mM}$ EDTA, $1 \mathrm{mM}$ PMSF) and lysed by sonication. The cell lysates were cleared by centrifugation $(27,000 \times g$ for $30 \mathrm{~min})$. Cleared lysates containing MBP, MBP-CesL or MBP-CesL ${ }_{\mathrm{C} \Delta 10}$ were incubated with $200 \mu \mathrm{L}$ of amylose resin (New England Biolabs) for $30 \mathrm{~min}$ at $4{ }^{\circ} \mathrm{C}$ with gentle shaking. The amylose resin coupled to MBP or MBP-tagged proteins was loaded onto a column and washed with $5 \mathrm{~mL}$ of lysis buffer. At this point, the cleared cell lysate containing SepD, SepL, His-Esc $V_{C}$, His-Esc $U_{C}$ or His-Esc $D_{N}$ was loaded into the column. Unbound proteins were washed three times with $5 \mathrm{~mL}$ of column buffer $(50 \mathrm{mM}$ Tris- $\mathrm{HCl} \mathrm{pH} 7.4,500 \mathrm{mM}$ $\mathrm{NaCl})$. In the case of the MBP-CesL $\mathrm{C}_{\mathrm{C} 10} / \mathrm{SepD}$ and MBP-CesL/SepD pull-downs, the final wash contained $1 \mathrm{M} \mathrm{NaCl}$. Proteins were eluted three times with $200 \mu \mathrm{L}$ of column buffer containing $20 \mathrm{mM}$ maltose.

To test the interaction between His-SepL, His-SepL $L_{\Delta 81-94}$ or His-SepL $\mathrm{L}_{\Delta 75}$ and SepD, $\mathrm{BDP}$ cells harboring plasmids $\mathrm{pMEpL}, \mathrm{pMEpL}_{\Delta 81-94}, \mathrm{pMEpL}_{\Delta 75}$ or $\mathrm{pATpD}$ were grown in $200 \mathrm{~mL}$ of $\mathrm{LB}$ at $37^{\circ} \mathrm{C}$ to an $\mathrm{OD}_{600}$ of $0.6-0.8$. Then, IPTG was added to a final concentration of $0.1 \mathrm{mM}$ and bacterial growth was continued for $4 \mathrm{~h}$ at $30^{\circ} \mathrm{C}$. Cells were collected by centrifugation at $8000 \times \mathrm{g}$ for $10 \mathrm{~min}$, resuspended in lysis buffer $(20 \mathrm{mM}$ Tris- $\mathrm{HCl} \mathrm{pH} \mathrm{7.4,}$ $500 \mathrm{mM} \mathrm{NaCl}, 10 \mathrm{mM}$ imidazole and $1 \mathrm{mM}$ PMSF) and lysed by sonication. The cell lysates were cleared by centrifugation $(27,000 \times g$ for $30 \mathrm{~min})$. Cleared lysates containing His-SepL, His-SepL ${ }_{\Delta 81-94}$ or His-SepL $\mathrm{L}_{\Delta 75}$ were incubated with $200 \mu \mathrm{L}$ of Ni-NTA resin for $30 \mathrm{~min}$ at $4{ }^{\circ} \mathrm{C}$ with gentle shaking. The protein-coupled resin was loaded into a column and washed with $5 \mathrm{~mL}$ of lysis buffer. Subsequently, the cleared cell lysate containing SepD was loaded into the column. Unbound proteins were washed three times with lysis buffer containing $30 \mathrm{mM}$ imidazole. Proteins were eluted three times with $200 \mu \mathrm{L}$ of lysis buffer containing $400 \mathrm{mM}$ imidazole.

\subsection{Bacterial Two-Hybrid Assay}

This assay is based on the modular nature of the transcriptional repressor LexA. This protein comprises an N-terminal DNA binding domain (DBD) and a C-terminal dimerization domain, and it binds to an operator site only as a dimer. The bait protein is fused to a mutant LexA DBD (LexA408) which binds to a mutant operator sequence and the prey protein is fused to a wild-type LexA DBD (LexAWT). Heterologous interactions between the proteins tested reconstitute the LexA heterodimer, which binds to a hybrid operator site, repressing the expression of the lac Z reporter gene [62]. The reporter E. coli SU202 strain was co-transformed with pSR658- and pSR659-based constructs (Table 1). Co-transformants were grown overnight in LB containing ampicillin, tetracycline and $1 \mathrm{mM}$ IPTG. Overnight cultures were used to inoculate fresh LB supplemented with $1 \mathrm{mM}$ IPTG and the appropriate antibiotics, and bacterial growth was continued until an $\mathrm{OD}_{600}$ of $0.4-0.6$ was reached. The $\beta$-galactosidase activity was determined as described by Miller [74]. Briefly, $100 \mu \mathrm{L}$ aliquots of each culture were mixed with $900 \mu \mathrm{L}$ of buffer $\mathrm{Z}$ $\left(60 \mathrm{mM} \mathrm{Na}_{2} \mathrm{HPO}_{4} \bullet 7 \mathrm{H} 2 \mathrm{O}, 40 \mathrm{mM} \mathrm{NaH}_{2} \mathrm{PO}_{4} \bullet \mathrm{H}_{2} \mathrm{O}, 100 \mathrm{mM} \mathrm{KCl}, 1 \mathrm{mM} \mathrm{MgSO}_{4} \bullet 7 \mathrm{H} 2 \mathrm{O}\right.$, $50 \mathrm{mM} \beta$-mercaptoethanol) $\mathrm{pH}$ 7.0. One drop of chloroform was added to the mixture and immediately vortexed for $30 \mathrm{~s}$ to lyse the cells. Then, $200 \mu \mathrm{L}$ of ortho-Nitrophenyl$\beta$-galactoside (ONPG) $(4 \mathrm{mg} / \mathrm{mL})$ were added and tubes were incubated at $30{ }^{\circ} \mathrm{C}$ for $30 \mathrm{~min}$. The reaction was stopped with $500 \mu \mathrm{L}$ of $1 \mathrm{M} \mathrm{NaCO} 3$ and the $\mathrm{OD}_{420}$ and $\mathrm{OD}_{550}$ was recorded. The Miller units were calculated as previously described [74]. Assays were performed in triplicate. Collected data were analyzed by a two-tailed Student's $t$-test using the GraphPad Prism software. 


\subsection{Yeast Two-Hybrid Assay}

The Matchmaker GAL4 two-hybrid system (Clontech) was used to evaluate proteinprotein interactions in yeast as previously described [20]. Saccharomyces cerevisiae strains PJ69-4 $\alpha$ (MAT- $\alpha$ ) and PJ69-4a (MAT-a) were transformed with pGBKT7 or pGADT7based constructs, respectively. Transformants were plated onto minimal synthetic-dropout medium lacking tryptophan (SD-Trp) or leucine (SD-Leu). Mating was carried out by coincubating the transformed MAT- $\alpha$ and MAT-a strains in Yeast Extract-Peptone-Dextrose (YPD) medium for $5 \mathrm{~h}$ at $30{ }^{\circ} \mathrm{C}$ with shaking. Cells harboring both plasmids were selected in SD-Trp-Leu plates. Protein interactions were selected by 10 -fold serial dilutions spotted ( $3 \mu \mathrm{L}$ of each dilution) onto SD-Trp-Leu-His medium. Plates were incubated for 3 to 9 days.

\subsection{Type III Secretion Assay}

EPEC strains were grown overnight at $37^{\circ} \mathrm{C}$ in LB medium supplemented with the appropriate antibiotics. Overnight cultures were used to inoculate (1:100 dilution) preequilibrated DMEM at $37^{\circ} \mathrm{C}$ in a $5 \% \mathrm{CO}_{2}$ atmosphere. Bacterial growth was continued under static conditions and the abovementioned parameters to an $\mathrm{OD}_{600}$ of $0.7-0.8$. Cells were harvested by centrifugation at $8000 \times g$ for $10 \mathrm{~min}$ and the cellular pellet was resuspended in $1 \times$ SDS-PAGE sample buffer. The proteins in the supernatant were precipitated overnight at $4{ }^{\circ} \mathrm{C}$ with $10 \% v / v$ trichloroacetic acid, and centrifuged at $18,100 \times g$ for $30 \mathrm{~min}$. The resulting protein pellet was resuspended in $1 \times$ SDS-PAGE sample buffer containing $10 \% v / v$ saturated Tris. Protein concentration in all samples was normalized according to each culture $\mathrm{OD}_{600}$ value.

\subsection{Cell Fractionation}

EPEC strains from overnight $\mathrm{LB}$ cultures were diluted 1:100 in $50 \mathrm{~mL}$ of pre-equilibrated DMEM and grown statically at $37^{\circ} \mathrm{C}$ in a $5 \% \mathrm{CO}_{2}$ atmosphere to an $\mathrm{OD}_{600}$ of $0.7-0.8$. Cells were collected by centrifugation at $8000 \times g$ for $10 \mathrm{~min}$, washed with $10 \mathrm{~mL}$ of phosphatebuffered saline, and centrifuged as described above. Bacterial cells were resuspended in $10 \mathrm{~mL}$ of $20 \mathrm{mM}$ Tris- $\mathrm{HCl} \mathrm{pH} 7.4$ supplemented with $1 \mathrm{mM}$ PMSF and disrupted by sonication. Samples were then centrifuged twice at $8000 \times g$ for $20 \mathrm{~min}$ to remove intact cells each time. The supernatant was ultracentrifuged at $90,400 \times g$ for $1 \mathrm{~h}$ at $4{ }^{\circ} \mathrm{C}$ to separate the cytoplasmic fraction (supernatant) from the membrane fraction (pellet). The membrane fraction was washed with $10 \mathrm{~mL}$ of cold Tris- $\mathrm{HCl} \mathrm{pH} \mathrm{7.4,} \mathrm{ultracentrifuged} \mathrm{as} \mathrm{above} \mathrm{and}$ resuspended in $1 \mathrm{~mL}$ of Tris- $\mathrm{HCl} \mathrm{pH} \mathrm{7.4.} \mathrm{Total} \mathrm{protein} \mathrm{content} \mathrm{was} \mathrm{quantified} \mathrm{by} \mathrm{Lowry}$ method [75]. To analyze proteins by immunodetection, $6 \mu \mathrm{g}$ of total protein were loaded and separated by SDS-PAGE.

\subsection{Immunoblotting}

Proteins were resolved on a 15\% SDS-PAGE and transferred onto PVDF or nitrocellulose membranes, which were then blocked overnight with $5 \% w / v$ non-fat milk in TBS-T (Tris-buffered saline with $0.1 \% v / v$ Tween 20). The following antibodies were used for immunoblotting: anti-EspA, anti-EspB, anti-EspF, anti-Map, anti-SepL, anti-SepD, antiEscQ, anti-EscJ, anti-CesL or anti-Tir polyclonal antibodies; as well as anti-DnaK (Enzo Life Sciences), horseradish peroxidase (HRP)-conjugated anti-FLAG (Sigma), anti-HA (Thermo Scientific) or anti-HIS (Santa Cruz Biotechnology) monoclonal antibodies. When required, membranes were probed with a secondary antibody (HRP-conjugated anti-rabbit or antimouse antibodies). Protein detection was carried out using the Western Chemiluminescent HRP Substrate kit (Millipore).

\subsection{Protein Stability Assay}

EPEC strains were grown overnight in LB and diluted 1:100 into $20 \mathrm{~mL}$ of preequilibrated DMEM. Bacterial growth was continued under static conditions at $37^{\circ} \mathrm{C}$ in a $5 \% \mathrm{CO}_{2}$ atmosphere until an $\mathrm{OD}_{600}$ of $0.7-0.8$ was reached. At this point, tetracycline $(20 \mu \mathrm{g} / \mathrm{mL})$ was added to stop de novo protein synthesis. Bacterial cultures were incubated 
under the same conditions and samples were taken every $15 \mathrm{~min}$ during $2 \mathrm{~h}$ to monitor SepL-FLAG, CesL-FLAG or untagged SepD protein levels by immunoblotting. Protein samples were normalized according to the $\mathrm{OD}_{600}$ value at each time point.

\subsection{Structural Modeling of the SepL/SepD/CesL Complex}

The models of the CesL and SepD proteins were generated using the I-TASSER server [76]. From the set of 5 possible models, the ones with the best C-score were chosen. For SepL modeling, residues 34-351 were threaded onto the solved structure of YopN32-277 from Yersinia pestis (PDB code 1XKP, chain A) [77] by specifying the use of YopN as a template. Once retrieved, each single protein model was separately fitted onto the crystal structure of the $Y$. pestis heterotrimeric complex (PDB code 1XKP) using the MatchMaker module implemented in UCSF Chimera [78] as follows: SepL was superimposed onto the structure of YopN, CesL onto the SycN structure and SepD onto the YscB structure. The orientation of the CesL protein model was manually adjusted so that the position of its C-terminus was consistent with the proposed SepD-binding region found in this work. The SepL/SepD/CesL heterotrimeric assembly was then refined with the GalaxyRefineComplex tool from GalaxyWEB server. GalaxyRefineComplex. Available online: http:/ / galaxy.seoklab.org/ (last accessed on 12 December 2020) [79]. Molecular images were prepared using UCSF Chimera.

\subsection{Coiled-Coil Prediction}

Coiled-coil formation was calculated using COILS version 2.1 with a sliding window size of 21 residues. COILS. Available online: https:/ / npsa-prabi.ibcp.fr/cgi-bin/npsa automat.pl?page=/NPSA/npsa_lupas.html (last accessed on 27 December 2020) [80].

\section{Results}

\subsection{CesL Differentially Regulates Translocator and Effector Protein Secretion}

The secretion phenotype of a CR cesL (orf12) mutant was reported to be a general defect in both translocator and effector protein secretion [54], and the same was observed for a cesL (10036) mutant in EHEC [60]. In contrast, a recent study showed that an EPEC cesL mutant is unable to secrete the translocator EspA but hypersecretes the effector Tir [48]. These contrasting results regarding the cesL mutant phenotype among $\mathrm{A} / \mathrm{E}$ pathogens are intriguing since the CesL proteins share more than $90 \%$ sequence identity. Here, we revisited the EPEC cesL mutant phenotype, demonstrating that CesL is indeed crucial for translocator protein secretion and negatively regulates effector protein secretion (Figure $1 \mathrm{~A}$ ). When compared to the wild-type strain, the secretion of EspA, EspB and EspD was completely abolished in the cesL mutant strain, while the effectors Tir, NleA, EspF, EspZ and Map were hypersecreted (Figure $1 \mathrm{~A}$ CBB, panel $S$ and Figure $1 C$, panel S). Furthermore, we showed that this phenotype is not due to an alteration in protein production in the ces $L$ background (Figure 1A, panel P). Complementation of the cesL mutant with plasmids expressing CesL or an N-terminally His-tagged version of the protein (His-CesL), restored the secretion of translocators and diminished the hypersecretion of effectors to wild-type levels (Figure 1A, CBB and panel S). The cesL mutant phenotype was also complemented by a C-terminally double HA-tagged version of the protein (CesL-HA) (see Figure 5A), indicating that the cesL mutant is nonpolar and that neither the $\mathrm{N}$ - nor the C-terminal epitope tags interfere with CesL protein function. Therefore, CesL is involved in the regulation of the secretion hierarchy. 
A
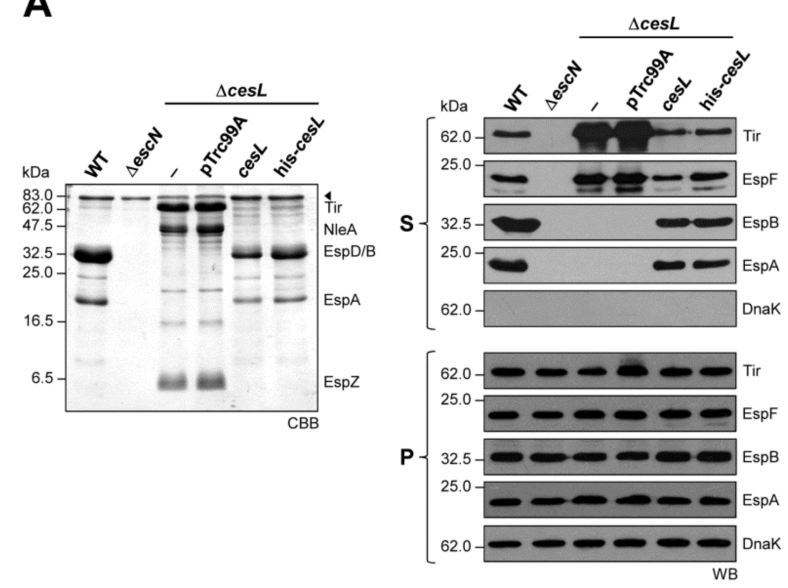

C

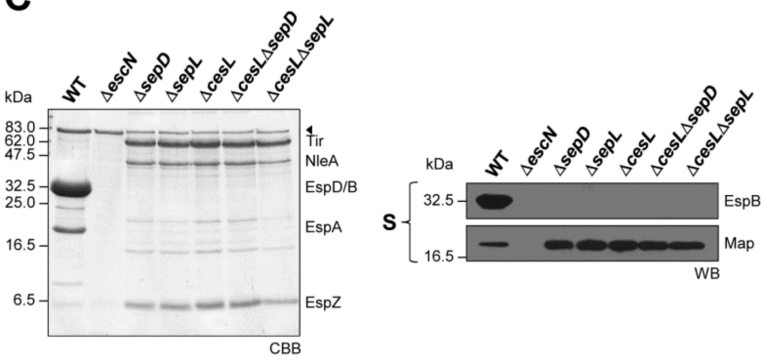

B
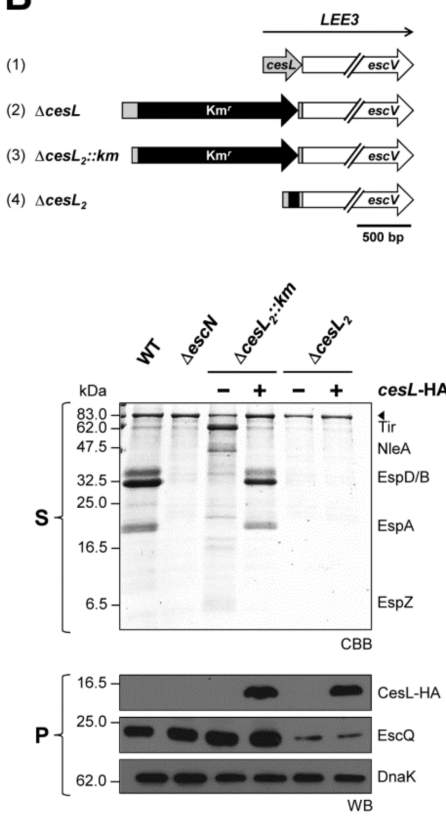

Figure 1. CesL protein is required for proper control of EPEC T3 secretion. (A) The EPEC wild-type strain (WT), $\triangle e s c N$ mutant strain, and $\Delta c e s L$ mutant strain (-) carrying an empty vector (pTrc99A_FF4), plasmid pMTcL (cesL) producing untagged CesL or plasmid pMTHcL (his-cesL) producing His-CesL were grown under T3S inducing conditions and the secreted protein content was examined. Protein samples were resolved on SDS-PAGE and stained with Coomassie brilliant blue (CBB). Proteins corresponding to T3SS substrates or the autotransporter EspC (arrowhead) are indicated on the right. Secreted proteins $(\mathrm{S})$ or whole-cell lysates $(\mathrm{P})$ were analyzed by immunoblotting using antibodies against the indicated protein (WB). (B) In-frame deletion of the first gene in the LEE3 operon results in a polar effect. Upper panel. Genetic organization of (1) wild-type cesL gene, (2) $\triangle$ cesL Km resistant mutant (3) equivalent CR orf12 deletion mutant in EPEC but with the kanamycin cassette $\left(\Delta c e s L_{2}:: \mathrm{km}\right)$, (4) the latter mutant without the kanamycin cassette $\left(\Delta c e s L_{2}\right)$. Lower panel. Secreted proteins $(\mathrm{S})$ and whole-cell lysates (P) of EPEC WT, the isogenic mutant $\triangle e s c N$, and the cesL knock-out mutant with $\left(\Delta c e s L_{2}:: \mathrm{km}\right)$ or without $\left(\Delta c e s L_{2}\right)$ the kanamycin resistance cassette, and carrying $(+)$ or not $(-)$ pMATcL2HA plasmid expressing CesL-HA. Protein samples were analyzed by CBB-stained SDSPAGE or immunoblotting with antibodies against the HA tag, the LEE3-encoded protein EscQ or the intracellular housekeeping chaperone DnaK. EspC is indicated with an arrowhead in CBB. (C) The EPEC $\Delta$ cesL mutant displays the same secretion phenotype as the $\Delta s e p D$ and $\Delta$ sepL mutants. Protein secretion profile of EPEC WT, $\Delta e s c N, \Delta s e p D, \Delta s e p L, \Delta c e s L$ and the $\Delta c e s L \Delta s e p D$ and $\Delta c e s L \Delta s e p L$ double mutants was analyzed by CBB-stained SDS-PAGE (left panel) or by immunoblotting using anti-EspB and anti-Map antibodies (WB, right panel). EspC is indicated with an arrowhead in CBB.

Based on these results, we investigated the difference between the previously reported C. rodentium and EHEC mutants versus the EPEC cesL mutant used in this study, which consists in the presence of a kanamycin cassette in the latter, while CR and EHEC were in frame deletions. Hence, we constructed the equivalent CR deletion mutant in EPEC $\left(c e s L_{2}\right)$, as well as this same mutant with a kanamycin cassette $\left(c e s L_{2}:: \mathrm{km}\right)$, and evaluated their phenotypes (Figure 1B). The results showed that the EPEC ces $L_{2}$ deletion mutant exerted a polar effect on downstream genes essential for T3S which are encoded in the same operon, as shown by a considerably decreased level of the EscQ protein (Figure 1B, panel $\mathrm{P}$, lanes $\left.\Delta c e s L_{2}\right)$, thus impeding type III secretion and in trans mutant complementation 
(Figure $1 \mathrm{~B}$, panel $\mathrm{S}$, lanes $\Delta c e s L_{2}$ ). However, when the kanamycin resistance gene is present, the phenotype of the mutant was identical to that of the $\Delta c e s L$ mutant and could be complemented in trans with plasmid-expressed CesL-HA (Figure 1B, panel S, lanes $\left.\Delta c e s L_{2}:: \mathrm{km}\right)$. The cesL mutant used in this work is also represented in Figure $1 \mathrm{~B}$, top, $(\Delta c e s L)$, in which sequences important for transcriptional regulation in the $5^{\prime}$ end of the gene were left intact [81].

In agreement with previous observations [48], we showed that the protein secretion profile of the cesL mutant is identical to the one reported for the sepD and sepL switch mutants (Figure 1C) $[36,48,54]$. In addition, we showed that the double mutants cesLsepD and cesLsepL exhibited the same phenotype as the single mutants (Figure 1C). These results are consistent with an earlier report showing that CesL associates with the SepD/SepL complex [59], and with our results of stable heterotrimeric complex formation (independently of which protein is tagged) (Figure S1), indicating that they act together in the regulation of ordered secretion.

\subsection{Pairwise Protein-Protein Interactions of CesL with SepD and SepL}

Based on a PSI-BLAST search as well as on secondary structure similarities, it was proposed that CesL is a homolog of SycN (a YopN gatekeeper chaperone), so it was classified as a class 1 chaperone for SepL, which in turn was shown to resemble an aberrant effector possessing a functional secretion signal [59]. However, a direct CesLSepL interaction has not been previously established. Hence, to characterize individual CesL interactions with SepD and SepL, we overproduced proteins in the same manner as for the heterotrimeric complex to perform co-purification assays under native conditions (see Figure S1). Nevertheless, upon protein induction of CesL with either SepL or SepD alone, CesL remained in the insoluble fraction; it was only soluble in the presence of both SepD and SepL (Figure S2). This result suggests that SepL and SepD interact with different domains of CesL, promoting its solubility.

In order to improve the solubility of CesL for pull down assays, we generated a maltose binding protein (MBP) N-terminally tagged version of the protein (MBP-CesL). Copurification assays showed that MBP-CesL was capable of retaining both untagged SepD (Figure 2A, left panel) and untagged SepL (Figure 2B, left panel), so that they co-eluted with MBP-CesL. MBP alone was used as a negative control (Figure 2A,B, right panels). It is worth noting that CesL shows an anomalous migration on SDS-PAGE.

These results were further confirmed using a bacterial two-hybrid system based on the E. coli LexA repressor (see Materials and Methods). In agreement with the abovementioned results, Figure $2 \mathrm{C}$ shows an interaction between CesL and both SepD and SepL, expressed as a statistically significant reduction in $\beta$-galactosidase activity compared to the respective protein tested against an empty vector. The previously known chaperone-effector (CesT-Tir) and the SepD-SepL protein-protein interactions $[58,82,83]$, were used as positive controls. Taken together, these results showed that CesL individually interacts with SepL and SepD, both of which also interact with each other, forming the heterotrimeric complex that regulates hierarchical secretion.

Furthermore, to dissect interaction domains between these proteins, we constructed truncated versions and analyzed their ability to interact with each other. The CesL interaction site on SepL maps to the amino terminal region within amino acids 30-75, since a SepL truncated version lacking the first 30 amino acids $\left(\operatorname{Sep}_{\Delta 30}\right)$ is able to form the heterotrimeric complex, while a SepL version lacking the first 75 amino acids $\left(\operatorname{SepL}_{\Delta 75}\right)$ forms a complex in which the interaction with SepD is not significantly affected but the one with CesL is severely diminished (Figure S3). This result further indicates that the SepD interaction site on SepL is beyond amino acid 75. Analysis of the SepL protein sequence revealed a predicted coiled-coil motif between amino acids 71-94 (see Materials and Methods), suggesting that such a motif may be important for the SepL-SepD interaction. Hence, we constructed a SepL deletion version lacking amino acids 81-94 (SepL $\left.L_{\Delta 81-94}\right)$ and assessed its interaction with SepD by co-purification and yeast two hybrid assays. The 
results showed that the protein interaction was abolished in both assays (Figure 3A), indicating that this SepL region is important for SepD binding. Moreover, it has been reported that a coiled-coil motif at the C-terminal region of the Salmonella SPI-2 encoded SsaM protein (a CesL homologue), is important for binding SpiC (a SepD homologue) [56]. Thus, although the CesL protein nowhere contains a predicted coiled-coil, a deletion version of this protein lacking the last 10 amino acids was constructed $\left(\operatorname{CesL}_{\mathrm{C} \Delta 10}\right)$, and its interaction with SepD was found to be considerably affected (Figure 3B). Considering these results, we evaluated the secretion phenotype of both mutant versions. The expression of either $\operatorname{SepL}_{\Delta 81-94}$ or $\operatorname{CesL}_{\mathrm{C} \Delta 10}$ from a low-copy number plasmid in the $\Delta$ sepL or $\Delta$ cesL background, respectively, did not reduce effector hypersecretion, but low level of translocators were found to be secreted, in contrast to complementation with full-length SepL or CesL that secretes similar levels of effectors and translocators to the wild-type strain (Figure 3C). These results suggest that formation of the heterotrimeric complex is important for proper hierarchical secretion and highlights the relevance of the interactions between CesL and SepD, and SepL and SepD, mainly to inhibit effector secretion.

\section{A}
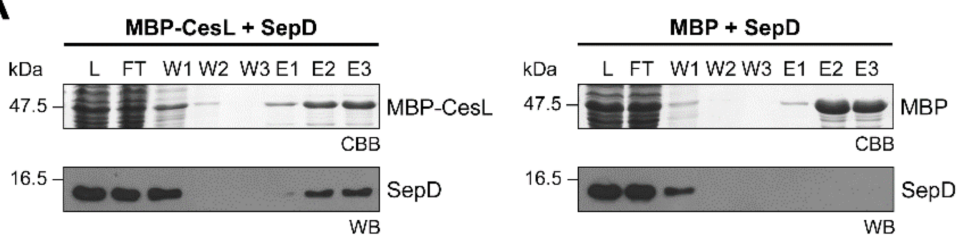

B
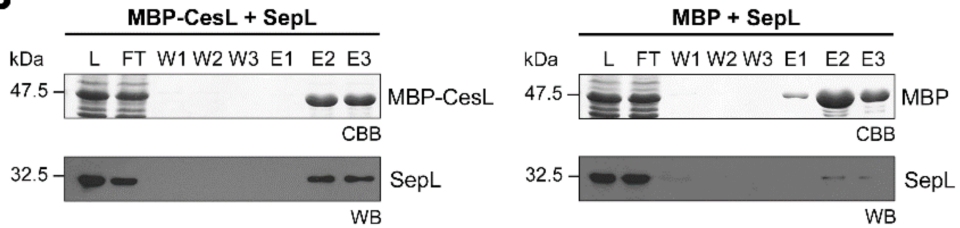

C

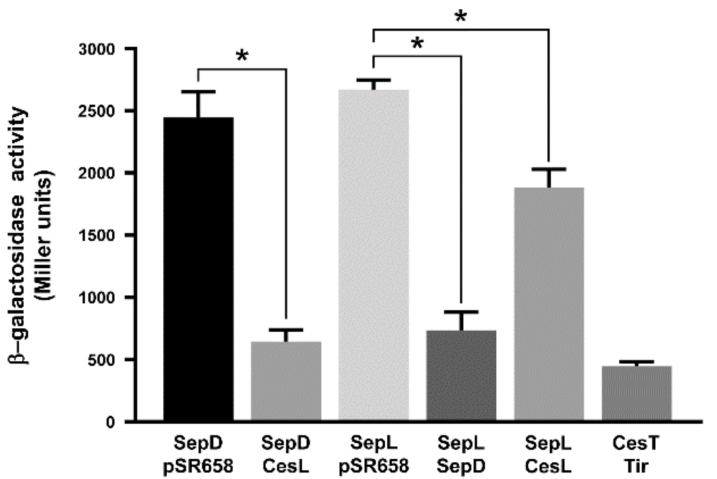

Figure 2. CesL associates independently with both SepD and SepL proteins. The MBP-CesL or MBP protein from a cleared cell lysate was immobilized on amylose resin and then a cleared lysate (L) containing either (A) untagged SepD or (B) untagged SepL was loaded onto the protein-coupled resin. Samples from the flow-through (FT), washes (W), and elutions (E) were collected and analyzed by CBB-stained SDS-PAGE and immunoblotting using anti-SepD or anti-SepL polyclonal antibodies. (C) Quantification of $\beta$-galactosidase activity of E. coli SU202 strain carrying plasmids pSR659 and pSR658 or derivatives thereof (expressing sepD, sepL, cesL, tir or cesT genes). The known SepD-SepL and CesT-Tir interactions were used as positive controls. Data represent the mean of three independent experiments in Miller units. Measurements were subjected to a 2-sided t-test to determine the statistical significance of the activity produced by the protein interactions compared to their respective negative control. ${ }^{*} p<0.005$. 
A

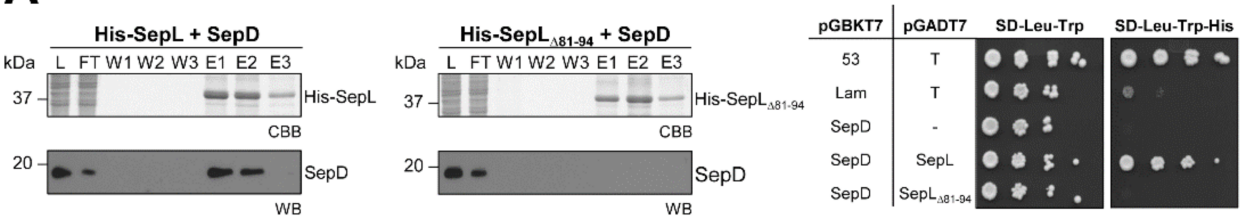

B
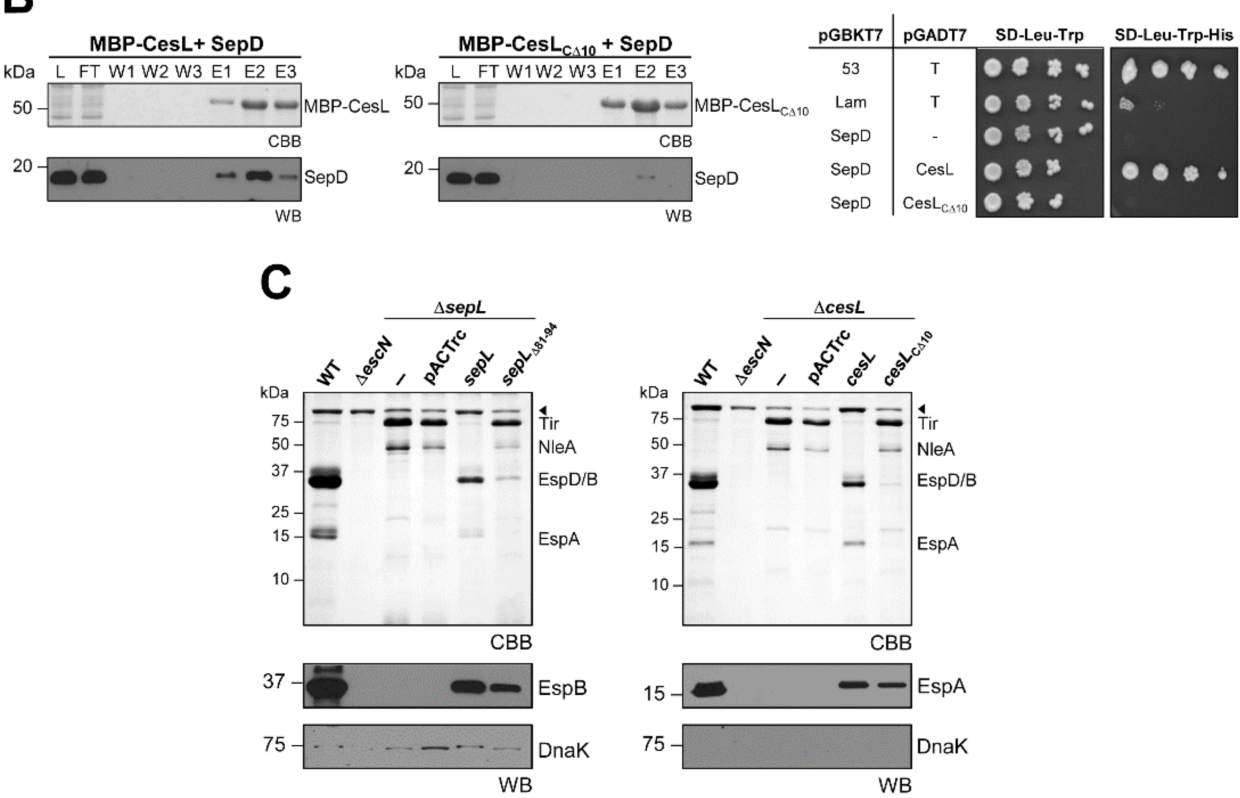

Figure 3. CesL and SepL interaction with SepD is required to regulate secretion hierarchy. (A) HisSepL or His-SepL $\mathrm{L}_{\Delta 1-94}$ and (B) MBP-CesL or MBP-CesL $\mathrm{C}_{\Delta 10}$ recombinant proteins were immobilized on Ni-NTA or amylose resin, respectively, and then a cleared lysate (L) containing untagged SepD was loaded onto the protein-coupled resin. Samples from the flow-through (FT), washes (W) and elutions (E) were collected and analyzed by CBB-stained SDS-PAGE and immunoblotting using anti-SepD antibodies (left panels). S. cerevisiae PJ69-4a / $\alpha$ strain carrying plasmids pGADT7 and pGBKT7 or their indicated derivatives was serially diluted and spotted onto SD-Leu-Trp medium as a growth control, and onto SD-Leu-Trp-His medium to test for protein interactions. The plasmid pairs pGADT7-T/pGBKT7-53 and pGADT7-T/pGBKT7-Lam were used as positive and negative controls, respectively. The plasmid pair pGBKT7-SepD/pGADT7-T was used as a SepD self-activation control (right panels). (C) Secreted proteins from EPEC wild-type strain (WT), $\Delta e s c N$ strain, and $\Delta s e p L$ (-) or $\Delta c e s L(-)$ strains harboring an empty vector (pACTrc), plasmid pMATpL expressing SepL, plasmid pMATpL $_{\Delta 81-94}$ expressing $\operatorname{SepL}_{\Delta 81-94}$, plasmid pMATcL expressing CesL or plasmid pMATcL $\mathrm{C}_{\Delta 10}$ expressing CesL $\mathrm{C}_{\mathrm{C} 10}$, were resolved on CBB-stained SDS-PAGE. Immunoblotting of EspB, EspA and DnaK proteins is shown (WB).

While the structure of almost the entire SepL protein (amino acids 80-350) has been solved [84], there is no structural information for neither SepD nor CesL proteins. Here, we built a model of the tertiary structure of the SepL/SepD/CesL heterotrimeric complex based on the crystal structure of the YopN-TyeA/YscB/SycN complex of Y. pestis (PDB ID:1XKP). The three dimensional structures of CesL and SepD were modeled using the I-TASSER prediction server [76]. Remarkably, the top templates that the algorithm used to generate the CesL and SepD structural models were SycN and other T3SS-related chaperones, respectively. As the N-terminal domain of YopN provides most of the contacts for its cognate partners, and such region of SepL has not been solved yet, we decided to model the SepL structure by guiding the algorithm using the YopN structure as template (see Materials and Methods). The predicted structures were fitted onto their respective counterpart on the YopN-TyeA/YscB/SycN complex, depicting the SepL/SepD/CesL heterotrimeric complex (Figure S4). The model suggests a larger molecular interface 
between CesL and SepD than the one between CesL and SepL, where only a very discrete portion of the SepL N-terminus is mediating the interaction.

\subsection{Stability of Both CesL and SepL Is Affected in the Absence of Each Other}

As abovementioned, CesL was proposed to be a chaperone for SepL [59]. To evaluate if CesL enhances the stability of SepL we performed protein stability assays in the presence of tetracycline to inhibit de novo protein synthesis. As shown in Figure 4A, the stability of functional chromosomally produced SepL-FLAG is negatively affected in the cesL mutant background, and this effect could be partially complemented when introducing a plasmid encoding CesL-HA. Besides, we also analyzed the stability of functional chromosomally produced CesL-FLAG. The result was unexpected for a predicted class 1 chaperone, as CesL stability was reduced in the sepL mutant background (Figure 4B). The CesL-FLAG stability defect could be complemented to wild-type levels when introducing the sepL gene in trans (Figure 4B). We also observed that the stability of SepD decreased in the absence of SepL and CesL, and that the stability of SepL and CesL is affected in a sepD mutant background (Figure S5). These results indicate that the stability of the three switch components is affected in the absence of each of their interacting partners, suggesting they function together as a protein complex. In this study we propose a model for the translocon to effector switching mechanism in EPEC, which depicts for the first time the existence of a heterotrimeric complex (see Discussion).

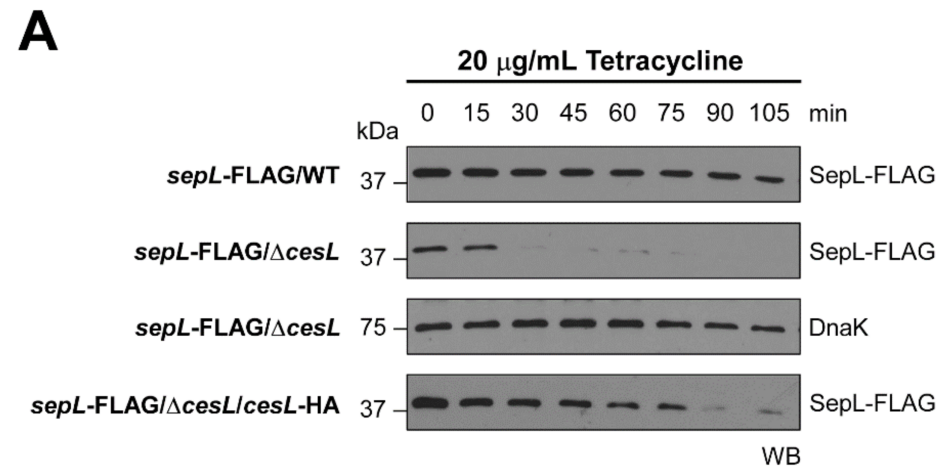

B

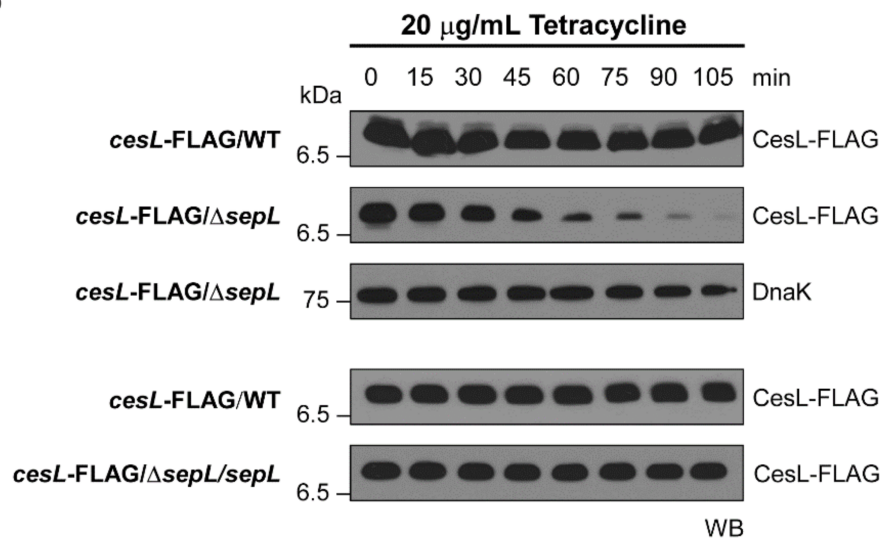

Figure 4. Interdependent stability of SepL and CesL proteins. (A) Immunoblotting showing the protein levels of chromosomally encoded SepL-FLAG expressed in wild-type EPEC (WT), $\triangle$ cesL mutant, and the $\triangle c e s L$ strain carrying plasmid pMATcL2HA producing CesL-HA. (B) Immunoblotting showing the protein levels of chromosomally encoded CesL-FLAG in wild-type EPEC (WT), $\triangle$ sepL mutant, and the $\triangle s e p L$ strain carrying plasmid pMATpL expressing untagged SepL. After halting de novo protein synthesis by addition of tetracycline, whole cell samples were collected every $15 \mathrm{~min}$ during $105 \mathrm{~min}$. DnaK was used as a protein loading control. Samples were normalized according to the culture $\mathrm{OD}_{600}$ at the time of collection. 


\subsection{CesL Is Not Secreted and Localizes to the Membrane Independently of SepD and SepL}

It is well known that various gatekeeper proteins are secreted in order to allow timely effector translocation $[39,43,44]$. Likewise, some proteins that form the gatekeeper complex have been reported to be secreted or translocated [44,47]. Thus, we evaluated whether CesL could be a T3SS substrate. The secretion profile of an HA C-terminally tagged version of CesL (CesL-HA) showed that this protein was not recovered in the supernatant fraction even though the translocators EspA and EspB were secreted (Figure 5A, left panel). In contrast, the EspH-HA effector was secreted in the wild-type strain and hypersecreted in the cesL mutant background, but not in the ATPase mutant used as a negative control (Figure 5A, right panel). The DnaK cytoplasmic chaperone was used as a loading control for whole cells.

A
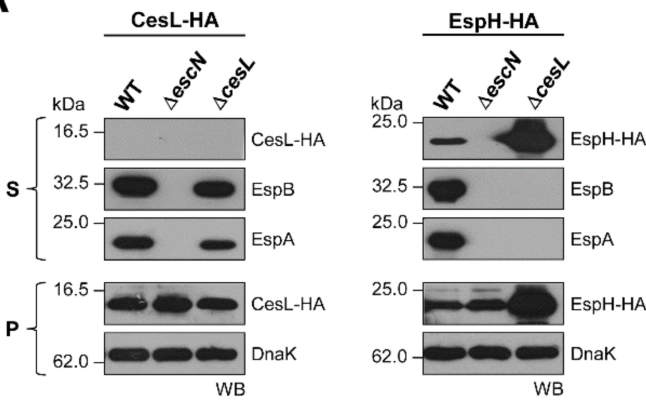

B
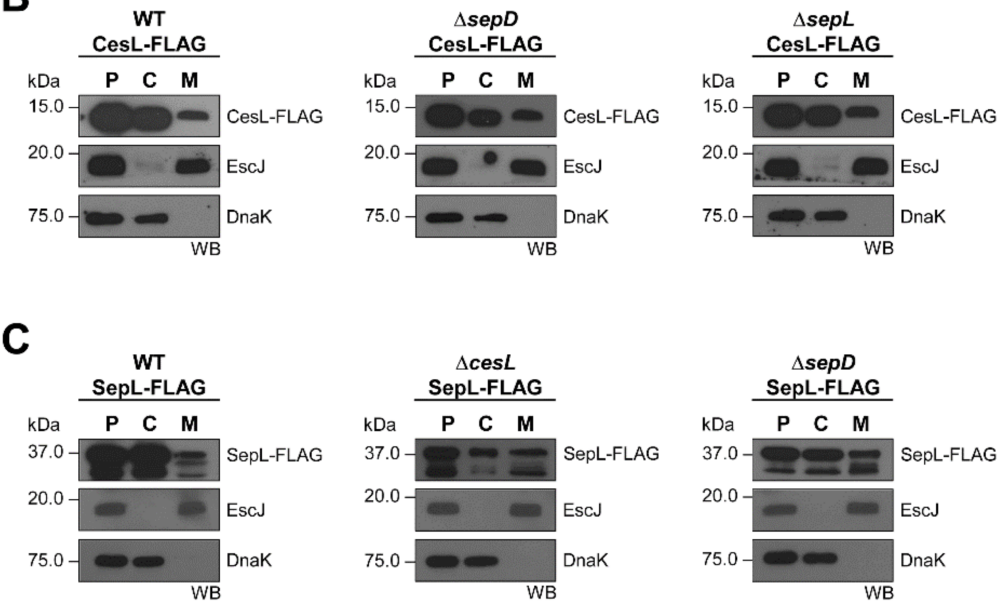

Figure 5. CesL and SepL associate with the membrane independently of their molecular switch interacting partners. (A) Secreted proteins (S) and whole-cell lysates (P) of wild-type EPEC (WT), $\triangle e s c N$ and $\triangle c e s L$ strains harboring plasmid pMHcL producing CesL-HA (left panel), or plasmid pJHeH producing EspH-HA (right panel), were subjected to SDS-PAGE and immunoblotting with an anti-HA antibody. The presence of EspB and EspA in the supernatant and that of DnaK in the bacterial pellet was also analyzed by immunoblotting. (B,C) Wild-type EPEC (WT), $\Delta s e p D$ and $\Delta s e p L$ strains expressing chromosomally encoded (B) CesL-FLAG or (C) SepL-FLAG. EPEC strains were grown under T3S-inducing conditions and fractionated into cytoplasmic $(\mathrm{C})$ and membrane $(\mathrm{M})$ fractions. Whole-cell lysates $(\mathrm{P})$ were loaded as a control. EscJ and DnaK were used as cytoplasmic and membrane protein controls, respectively. Equal amounts of each fraction were probed using antibodies against the FLAG tag, EscJ, or DnaK.

In order to determine the localization of CesL, bacteria were fractionated into cytoplasmic and membrane fractions, and the protein was identified using antibodies against the C-terminal FLAG tag, as detailed in Materials and Methods. In wild-type EPEC, CesL was detected in both the cytoplasmic and membrane fractions (Figure 5B, left panel), which is consistent with the location previously reported for SepL and SepD [36]. The inner 
membrane ring protein EscJ was used as a membrane fraction control and DnaK as a cytoplasmic fraction control. We next examined whether the localization of CesL was affected in the absence of the other components of the gatekeeper complex. As seen in Figure 5B (middle and right panels), the localization of CesL-HA was not altered in the sepD and sepL mutants. This result suggests that CesL is intrinsically targeted to the inner membrane.

Additionally, we evaluated if the membrane localization of SepL was dependent on CesL and SepD. Chromosomally produced FLAG tagged SepL (SepL-FLAG) was localized in both the cytoplasmic and membrane fractions independently of the presence of CesL and SepD (Figure 5C). In agreement, the same result was obtained when using untagged SepL expressed from a low-copy number plasmid (Figure S6).

\subsection{CesL Interacts with Both Components of the Export Gate}

The cytoplasmic C-terminal domain of two of the membrane components of the export apparatus $\left(E s c U_{C}\right.$ and $\left.E_{s c} V_{C}\right)$, forms the export gate through which substrates are secreted [5]. We and others have previously demonstrated that the gatekeeper SepL interacts with the soluble domain of $\mathrm{EsCV}$ and that this interaction is important for a proper secretion hierarchy $[48,49]$. Likewise, here we show that CesL interacts with $\operatorname{EscV}_{C}$ (Figure 6A), suggesting that it is the SepL/SepD/CesL complex the one modulating the conformational changes in EscV that lead to differential substrate recognition. Remarkably, the CesL protein also interacted with $\mathrm{EscU}_{\mathrm{C}}$ (Figure $6 \mathrm{~B}$ ), which is involved in the first specificity switching event, from early to intermediate and late substrates $[35,85,86]$. MBP alone was used as a negative control (Figure 6A,B, right panels). Moreover, we tested the MBP-CesL interaction with another IM protein, EscD, which forms one of the basal body inner membrane rings. The result showed that the soluble N-terminal domain of the EscD protein $\left(\operatorname{EscD}_{\mathrm{N}}\right)$ did not interact with MBP-CesL, indicating the non-existence of an MBP-CesL unspecific interaction (Figure 6C).

A
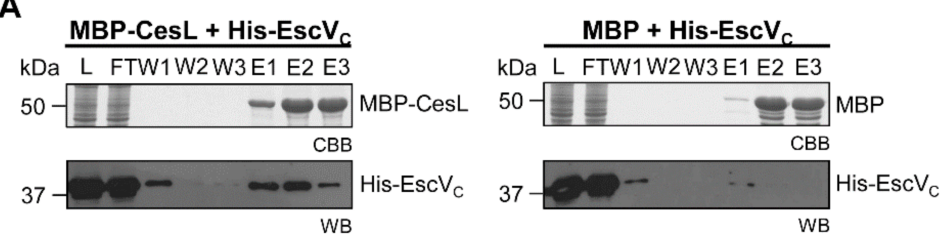

B
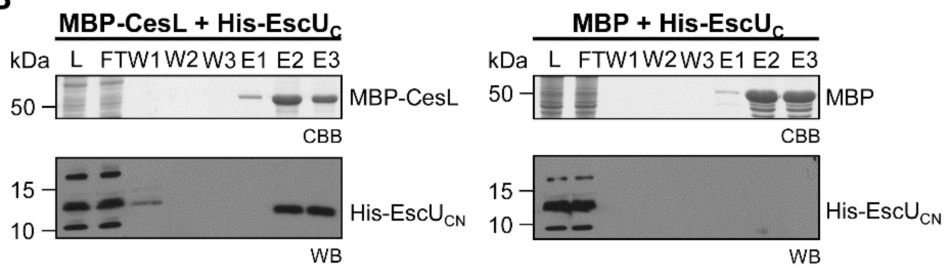

C

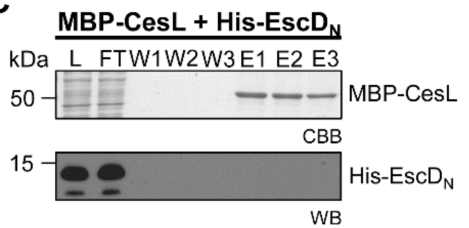

Figure 6. CesL interacts with the export gate components EscV and EscU. MBP-CesL (left panels) or MBP (right panels) was bound to a packed amylose resin and a cleared lysate (L) containing the His-tagged cytoplasmic domain of $(\mathbf{A}) \operatorname{EscV}\left(\operatorname{EscV}_{\mathrm{C}}\right)$ or $(\mathbf{B}) \operatorname{EscU}\left(\operatorname{Esc}_{\mathrm{C}}\right)$ and the mixture was loaded into the column. Samples from the flow-through (FT), washes (W) and elutions (E) were collected and analyzed by CBB-stained SDS-PAGE and immunoblotting (WB) using anti-EscV $\mathrm{V}_{\mathrm{C}}$ or anti-EscU polyclonal antibodies. (C) The His-tagged cytoplasmic domain of EscD (EscD $\left.{ }_{N}\right)$ did not copurify with MBP-CesL and was used as a negative control. 


\section{Discussion}

The T3SS is a recurrent theme in bacterial pathogenesis. The proper assembly and functioning of this sophisticated nanomachine depends on the orchestrated secretion of its component proteins $[33,87]$. This process is regulated by two molecular specificity switches, which guarantee that bacterial effectors are delivered directly into the host cell [5] Although recent advances have markedly increased our understanding of the function of these two regulatory complexes, the precise molecular mechanisms preventing a futile secretion of effectors are largely unknown. In EPEC, the SepL/SepD complex has been found to have a major role in the regulation of substrate specificity switching [36,48]. Our data shows that the CesL component of the gatekeeper complex has a direct role in finetuning the orderly secretion of T3 substrates. We propose a model in which CesL facilitates a crosstalk between the two molecular switches.

Contrasting phenotypes have been reported for cesL deletion mutants in CR, EHEC and EPEC $[48,54,60]$. Hence, as a first step to clarify the function of CesL, we constructed a set of cesL deletion strains in EPEC with and without a kanamycin resistance cassette. Consistent with the phenotype reported by Portaliou et al. [48], we have shown that CesL is essential for translocator secretion and negatively regulates effector secretion (Figure 1A), in an identical manner as sepL and sepD mutants (Figure 1C). Further, we showed that the different phenotypes are attributed to the presence/absence of the $\mathrm{km}$ resistance cassette. The in frame deletion of cesL in EPEC $\left(\triangle c e s L_{2}\right)$ had a polar effect on the expression of downstream genes in the $L E E 3$ operon $c e s L, e s c V, e s c N, e s c O, e s c P$, esc $Q$ and $e s p H$ (all of which are essential for T3S except for espH), and thus protein secretion was abolished (Figure 1B). However, this effect was overcome by the insertion of the km cassette, which probably drives the transcription and subsequent translation of downstream genes. This result is consistent with what has been observed in EHEC, where translation of 10036 (cesL) is needed for the synthesis of downstream gene products [60]. However, our results indicate that it is not the translation of cesL per se, but that of any other gene, which presumably protects the LEE3 transcript from being degraded. Our proposal is in agreement with recent observations for the LEE5 operon, where translation of tir, the first gene of the operon, is needed to prevent degradation of the LEE5 transcript [88]. Overall, our results confirm a role of CesL in the regulation of ordered secretion.

The EPEC SepL/SepD/CesL ternary complex resembles the Salmonella SsaL/SpiC/SsaM, Yersinia YopN-TyeA/YscB/SycN, Pseudomonas PopN-Pcr1/PscB/Pcr2, Chlamydia CopN/Scc4/Scc1 and Edwarsiella EsaL/EsaB/EsaM regulatory complexes needed for the organized secretion of T3 substrates in homologous systems $[42,44,46,59,77,89]$. It has been reported that the N-terminal region of some gatekeepers such as YopN, PopN and CopN interacts with heterodimeric chaperone complexes (YscB/SycN, PscB/Pcr2 and Scc4/Scc1, respectively), which stabilize and target the gatekeeper to the export apparatus for its secretion $[44,55,77]$. However, unlike these previous reports, we showed that CesL and SepD can bind to SepL independently (Figure 2), suggesting that a preformed SepD/CesL chaperone complex is not required for binding to the gatekeeper. These pairwise interactions are in agreement with those reported for the EsaL/EsaB/EsaM complex in E. tarda, where EsaB (SepD homologue) and EsaM (CesL homologue) can individually interact with EsaL (SepL homologue). Additionally, in accordance to what we observed, the EsaB and EsaM proteins can interact between them independently of EsaL [42].

Coiled-coil motifs have been found to mediate protein-protein interactions and their importance in T3S systems have been previously reported [90]. SepL possesses a predicted coiled-coil motif at its N-terminal domain, and remarkably, several SepL homologues share this structural characteristic in the same region. Here, we demonstrate that the integrity of this motif is crucial for SepD binding (Figure 3A). It is noteworthy that the atomic structure of this region of SepL remains unsolved [84]. Likewise, we found that the Cterminal region of CesL is also critical for SepD interaction (Figure 3B). Functional analysis further confirmed the importance of these interfaces for secretion regulation (Figure 3C). Remarkably, both truncated versions that abrogate the interaction with SepD were unable 
to prevent effector hypersecretion in complementation assays. On the other hand, the secretion of translocators was partially restored. These results suggest that the main role of SepD in hierarchy regulation is to stop premature effector secretion, and that a proper heterotrimeric complex must be formed to achieve this function.

Furthermore, our results suggest that the interaction region between CesL and SepL maps within SepL amino acids 30 to 75 (Figure S3). The interacting domains at the Nterminus of SepL are supported by our in silico modeling of the gatekeeper complex, in which this region adopts an extended conformation that binds both CesL and SepD (Figure S4). Further structural studies of the entire heterotrimeric complex are needed to define the precise arrangement of its components.

CesL and SepD were previously proposed to function as chaperones [59]. In agreement with this role, the stability of SepL was severely affected in the absence of these proteins. However, unexpectedly, the stability of CesL and SepD was also compromised in a sepL mutant background. Therefore, formation of the trimeric complex is important for protein stability. Albeit that CesL is able to interact in vitro with SepL and SepD in a pairwise manner, our study demonstrates that the formation of the heterotrimeric complex is crucial for stability of these proteins within bacterial cells (Figure 4 and Figure S5).

Several gatekeeper proteins are known to be secreted in a T3SS-dependent manner; however, we showed that CesL is not secreted into the culture supernatant (Figure 5A). Nevertheless, it was recently reported that the Vibrio parahaemolyticus gatekeeper proteins VgpA and VgpB are translocated into host cells [47]. Since these proteins are not secreted in vitro, further studies will be needed to explore an additional extracellular role of EPEC switch proteins during the infection process. Ours and other previous studies have shown that SepL and its gatekeeper binding partners exist in both a soluble and a membraneassociated pool $[36,49,57,91]$. In this work we showed that CesL and SepL displayed the same localization pattern independently of other components of the gatekeeper complex (Figure 5B,C and Figure S6). These results are consistent with a previous report showing that SepL localization is not affected in the absence of SepD [48], but are in contrast with data showing that the membrane localization of untagged SepL or a SepL-eGFP version is disrupted in the absence of CesL [48] or of SepD [91], respectively. These discrepancies could be due to methodological differences in the fractionation procedure, or to the presence of a large tag such as the GFP protein.

The T3S inner membrane proteins EscV and EscU are crucial components of the EPEC injectisome, and their large cytoplasmic domains reside at the entry of the export gate, where they have direct access to T3 substrates right before entering the secretion pathway. Here, we found that in addition to SepL, CesL is able to interact with EscV. Moreover, we report the formation of a novel protein complex composed by CesL and EscU (Figure 6). The functional relevance of these CesL complexes remains unclear, although we propose a model where they might be coupling the first and second molecular switches (see below).

Taken together, our data suggest that CesL does not act as a canonical chaperone, but rather plays an active role in the regulation of the secretion hierarchy.

Taking into account the data presented here and results from previous studies, we propose a model for regulation of EPEC type III secretion as shown in Figure 7. (i) Esc $U_{C}$ $\left(\mathrm{SctU}_{\mathrm{C}}\right)$ is autocleaved into two subdomains, $\mathrm{EscU}_{\mathrm{CN}}$ and $\mathrm{Esc}_{\mathrm{CC}}$ that remain tightly associated $[85,86,92]$. In the first assembly stage, autocleaved EscU and the ruler protein EscP modulate the secretion of the early substrates EscI and EscF, necessary for the assembly of the inner rod and needle. During formation of these structures EscP is also occasionally secreted [35]. (ii) When the needle reaches its proper length, EscP productively interacts with EscU to stop secretion of early substrates and to streamline the substrate specificity switching to middle substrates, allowing recognition of translocators and positively influencing the SctW gatekeeper interaction with the SctV export gate component, as reported for Salmonella SPI-2 [35,50]. (iii) In this same regard, we suggest that the CesL-EscU interaction demonstrated in this work could play a role in promoting the SepL-EscV interaction, thereby communicating that the first substrate switching event has occurred. In this second 
stage, translocators are secreted while, simultaneously, the premature secretion of effectors is blocked. This is regulated by the SepL/SepD/CesL molecular switch in complex with EscV, which works as a docking platform with high affinity for translocator-chaperone complexes and which inhibits binding of effector-chaperone complexes $[48,49]$. (iv) It has been reported that SctU is present in a stoichiometry of one subunit within the export apparatus [22,93], thus it is possible that the interaction with one EscP molecule could flip the specificity switch. The remnant EscP protein could be located at the inner membrane in complex with SepL, sequestering the CesT/Tir complex, since interactions between these proteins have been observed, and $\mathrm{EscP}$ has been reported to be associated with the membrane $[35,61,91]$. (v) Once the EspA filament has been assembled and the translocation pore is formed in the host cell membrane, the cell contact signal is transmitted to the export apparatus through conformational changes in the filament/needle [37-40]. Consequently, the SepL/SepD switch proteins (in complex with CesL shown here to interact with EscVc), disengage from $\mathrm{EscV}$ allowing effector secretion. The EscVc platform thereby changes its conformation to bind effector-chaperone complexes with high affinity [48]. In addition, the formation of a SepL-EscP complex was reported to participate in regulation of effector secretion [61]. It has been suggested that host cell contact produces a drop in calcium concentration at the base of the injectisome [36], which was shown to disrupt the SepL-EscP interaction [61], which in turn releases the CesT-Tir complex to initiate effector translocation $[35,61]$.

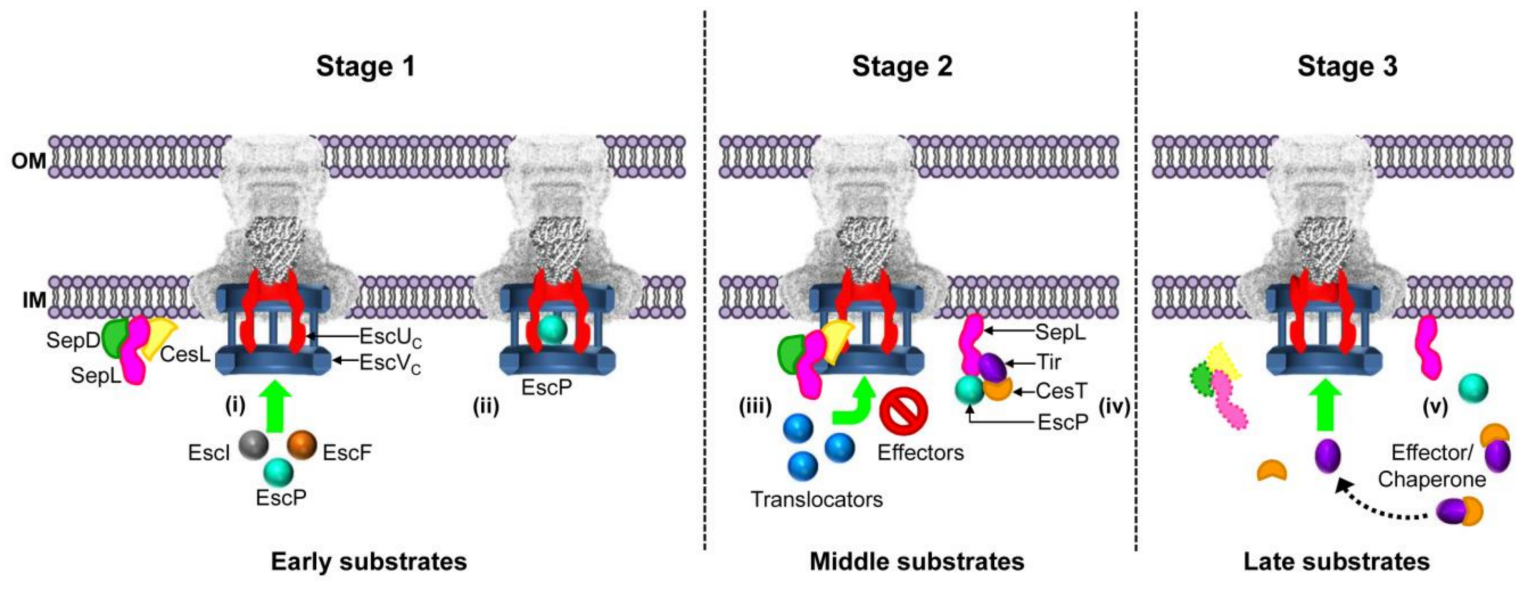

Figure 7. Model for regulation of type III secretion hierarchy. During T3SS assembly, two molecular switches ensure that the different substrates are secreted in a hierarchical order. Stage 1. (i) Early substrates are secreted. At this time, the molecular switch proteins SepL, SepD and CesL (in complex or independently), are associated with the membrane and likely located near the export apparatus. (ii) When the needle reaches its predetermined length, EscP interacts with Esc $\mathrm{U}_{\mathrm{C}}$, promoting a conformational change that flips the first substrate specificity switch, thereby halting early substrate secretion and allowing (together with the SepL/SepD/CesL complex) middle substrate recognition (see next stage). Stage 2. (iii) The first specificity switching event is transmitted to the EscV export gate component via interactions of the SepL/SepD/CesL heterotrimeric complex with both EscU and EscV. This communication enables middle substrates to be recognized and secreted by the EscV docking platform. (iv) At the same time, EscP bound to SepL sequesters the chaperone-effector CesT/Tir complex. Stage 3. (v) Once the translocation pore has been inserted into the host cell membrane, an activation signal is transmitted to the export apparatus, which results in switch complex dissociation, permitting late substrates binding to EscV and effector translocation. In addition, it has been shown that a drop in calcium concentration dissociates the SepL-EscP interaction, releasing the CesT/Tir complex for docking at EscV.

Our working model regarding the functionality of the newly described EscU-CesL interaction is supported by recent experimental evidence from the Salmonella SPI-2 T3SS, where in the absence of SsaP (SctP), or in the presence of a non-cleaved form of SsaU (SctU), the binding of SsaV (SctV) with the gatekeeper SsaL (SctW) is diminished [50]. Moreover, in the flagellar system it has been shown that the interaction of FliK (SctP) with the cleaved form of $\mathrm{FlhB}_{\mathrm{C}}\left(\mathrm{SctU}_{\mathrm{C}}\right)$, ends the secretion of hook type substrates (early 
substrates in the injectisome) and promotes structural changes in the cytoplasmic domain of FlhA $(\mathrm{SctV})$. The direct interaction of $\mathrm{FlhB}_{\mathrm{C}}$ with $\mathrm{FlhA}_{\mathrm{C}}$ enables the latter to adopt an open conformation that recognizes the next substrate category, namely, filament type substrates (middle substrates in the injectisome) [94-96]. Overall, these data indicate the existence of an interconnection between both molecular switches. Moreover, our results showed an additional direct role of CesL in the secretion process and contribute to increase our understanding of the molecular switches and how they are related to each other in order to define the secretion hierarchy.

In addition to the main function of the gatekeeper complex in switching substrate specificity from translocators to effectors, current knowledge indicates that the gatekeeper SctW also regulates the secretion of early substrates by promoting the docking of chaperonesubstrate complexes to the ATPase SctN [97], highlighting the relevance of this protein complex in the T3SS.

Therefore, the knowledge gained on the functioning of the gatekeeper complex could have implications for its use as a therapeutic target, or as a secretion regulator of a biotechnological vehicle to inject modified proteins. Indeed, the T3SS of EPEC has already been genetically engineered to translocate proteins of interest into mammalian cells [98].

Supplementary Materials: The following are available online at https: / www.mdpi.com/article / 10.3390 /microorganisms 9051047 /s1, Figure S1. Formation of stable heterotrimeric complexes by pull-down assays. Figure S2. Solubility of His-CesL requires both SepL and SepD proteins. Figure S3. Role of the N-terminal region of SepL in the formation of the heterotrimeric complex. Figure S4. Three-dimensional structural modeling of the EPEC SepL/SepD/CesL complex. Figure S5. In vivo stability of SepL, SepD, and CesL proteins depends on each other. Figure S6. SepL membrane location is not affected in the absence of CesL or SepD.

Author Contributions: Experimental data acquisition and writing-original draft preparation, M.D.-G., A.M.-V., M.O.G., E.S., E.G.-G., N.E. and A.A.; bioinformatics and statistical analysis, E.S.; methodology, N.E.; review and editing, M.O.G., E.G.G. and A.A.; project administration, funding acquisition and writing - review and editing, B.G.-P. All authors have read and agreed to the published version of the manuscript.

Funding: This research was funded by grants from Dirección General de Asuntos del Personal Académico, UNAM (PAPIIT-IN212420) and Consejo Nacional de Ciencia y Tecnología (CONACyT) (284081). This study was also supported by a fellowship from CONACyT project 284081 to M.D-G.

Institutional Review Board Statement: Not applicable.

Informed Consent Statement: Not applicable.

Data Availability Statement: Not applicable.

Acknowledgments: We are very grateful to José Luis Puente García at IBt, UNAM for the kind donation of E. coli strains and plasmids, and for constant advice. We acknowledge Claudia Rivera Cerecedo and Héctor Malagón Rivero at Bioterio-IFC, UNAM; Laura Ongay, Guadalupe Códiz and Minerva Mora at UBM-IFC, UNAM and Gerardo Coello, Juan Barbosa Castillo and Ivette Rosas Arciniega at Unidad de Cómputo at IFC, UNAM, for excellent technical assistance.

Conflicts of Interest: The authors declare no conflict of interest.

\section{References}

1. Nataro, J.P.; Kaper, J.B. Diarrheagenic Escherichia coli. Clin. Microbiol. Rev. 1998, 11, 142-201. [CrossRef] [PubMed]

2. Moon, H.W.; Whipp, S.C.; Argenzio, R.A.; Levine, M.M.; Giannella, R.A. Attaching and effacing activities of rabbit and human enteropathogenic Escherichia coli in pig and rabbit intestines. Infect. Immun. 1983, 41, 1340-1351. [CrossRef] [PubMed]

3. Chen, H.D.; Frankel, G. Enteropathogenic Escherichia coli: Unravelling pathogenesis. FEMS Microbiol. Rev. 2005, 29, 83-98. [CrossRef] [PubMed]

4. Bhatt, S.; Egan, M.; Critelli, B.; Kouse, A.; Kalman, D.; Upreti, C. The Evasive enemy: Insights into the virulence and epidemiology of the emerging attaching and effacing pathogen Escherichia albertii. Infect. Immun. 2019, 87. [CrossRef]

5. Gaytan, M.O.; Martinez-Santos, V.I.; Soto, E.; Gonzalez-Pedrajo, B. Type Three secretion system in attaching and effacing pathogens. Front. Cell. Infect. Microbiol. 2016, 6, 129. [CrossRef] 
6. Slater, S.L.; Sagfors, A.M.; Pollard, D.J.; Ruano-Gallego, D.; Frankel, G. The type III secretion system of pathogenic Escherichia coli. Curr. Top. Microbiol. Immunol. 2018, 416, 51-72. [CrossRef]

7. Yerushalmi, G.; Litvak, Y.; Gur-Arie, L.; Rosenshine, I. Dynamics of expression and maturation of the type III secretion system of enteropathogenic Escherichia coli. J. Bacteriol. 2014, 196, 2798-2806. [CrossRef]

8. McDaniel, T.K.; Jarvis, K.G.; Donnenberg, M.S.; Kaper, J.B. A genetic locus of enterocyte effacement conserved among diverse enterobacterial pathogens. Proc. Natl. Acad. Sci. USA 1995, 92, 1664-1668. [CrossRef]

9. Gomes, T.A.T.; Ooka, T.; Hernandes, R.T.; Yamamoto, D.; Hayashi, T. Escherichia albertii Pathogenesis. EcoSal Plus 2020, 9. [CrossRef]

10. Deng, W.; Yu, H.B.; de Hoog, C.L.; Stoynov, N.; Li, Y.; Foster, L.J.; Finlay, B.B. Quantitative proteomic analysis of type III secretome of enteropathogenic Escherichia coli reveals an expanded effector repertoire for attaching/effacing bacterial pathogens. Mol. Cell. Proteom. 2012, 11, 692-709. [CrossRef]

11. Dean, P.; Kenny, B. The effector repertoire of enteropathogenic E. coli: Ganging up on the host cell. Curr. Opin. Microbiol. 2009, 12, 101-109. [CrossRef]

12. Deng, W.; Marshall, N.C.; Rowland, J.L.; McCoy, J.M.; Worrall, L.J.; Santos, A.S.; Strynadka, N.C.J.; Finlay, B.B. Assembly, structure, function and regulation of type III secretion systems. Nat. Rev. Microbiol. 2017, 15, 323-337. [CrossRef]

13. Diepold, A.; Armitage, J.P. Type III secretion systems: The bacterial flagellum and the injectisome. Philos. Trans. R. Soc. Lond. B Biol. Sci. 2015, 370. [CrossRef]

14. Abby, S.S.; Rocha, E.P. The non-flagellar type III secretion system evolved from the bacterial flagellum and diversified into host-cell adapted systems. PLoS Genet. 2012, 8, e1002983. [CrossRef]

15. Pal, R.R.; Baidya, A.K.; Mamou, G.; Bhattacharya, S.; Socol, Y.; Kobi, S.; Katsowich, N.; Ben-Yehuda, S.; Rosenshine, I. Pathogenic E. Coli extracts nutrients from infected host cells utilizing injectisome components. Cell 2019, 177, 683-696. [CrossRef]

16. Hueck, C.J. Type III protein secretion systems in bacterial pathogens of animals and plants. Microbiol. Mol. Biol. Rev. 1998, 62, 379-433. [CrossRef]

17. Wagner, S.; Diepold, A. A unified nomenclature for injectisome-type type III secretion systems. Curr. Top. Microbiol. Immunol. 2020, 427, 1-10. [CrossRef]

18. Andrade, A.; Pardo, J.P.; Espinosa, N.; Perez-Hernandez, G.; Gonzalez-Pedrajo, B. Enzymatic characterization of the enteropathogenic Escherichia coli type III secretion ATPase EscN. Arch. Biochem. Biophys. 2007, 468, 121-127. [CrossRef]

19. Romo-Castillo, M.; Andrade, A.; Espinosa, N.; Monjaras Feria, J.; Soto, E.; Diaz-Guerrero, M.; Gonzalez-Pedrajo, B. EscO, a functional and structural analog of the flagellar FliJ protein, is a positive regulator of EscN ATPase activity of the enteropathogenic Escherichia coli injectisome. J. Bacteriol. 2014, 196, 2227-2241. [CrossRef]

20. Soto, E.; Espinosa, N.; Diaz-Guerrero, M.; Gaytan, M.O.; Puente, J.L.; Gonzalez-Pedrajo, B. Functional Characterization of EscK (Orf4), a Sorting Platform Component of the Enteropathogenic Escherichia coli Injectisome. J. Bacteriol. 2017, 199. [CrossRef]

21. Biemans-Oldehinkel, E.; Sal-Man, N.; Deng, W.; Foster, L.J.; Finlay, B.B. Quantitative proteomic analysis reveals formation of an EscL-EscQ-EscN type III complex in enteropathogenic Escherichia coli. J. Bacteriol. 2011, 193, 5514-5519. [CrossRef] [PubMed]

22. Kuhlen, L.; Johnson, S.; Zeitler, A.; Baurle, S.; Deme, J.C.; Caesar, J.J.E.; Debo, R.; Fisher, J.; Wagner, S.; Lea, S.M. The substrate specificity switch FlhB assembles onto the export gate to regulate type three secretion. Nat. Commun. 2020, 11, 1296. [CrossRef] [PubMed]

23. Abrusci, P.; Vergara-Irigaray, M.; Johnson, S.; Beeby, M.D.; Hendrixson, D.R.; Roversi, P.; Friede, M.E.; Deane, J.E.; Jensen, G.J.; Tang, C.M.; et al. Architecture of the major component of the type III secretion system export apparatus. Nat. Struct. Mol. Biol. 2013, 20, 99-104. [CrossRef] [PubMed]

24. Hu, B.; Morado, D.R.; Margolin, W.; Rohde, J.R.; Arizmendi, O.; Picking, W.L.; Picking, W.D.; Liu, J. Visualization of the type III secretion sorting platform of Shigella flexneri. Proc. Natl. Acad. Sci. USA 2015, 112, 1047-1052. [CrossRef]

25. Butan, C.; Lara-Tejero, M.; Li, W.; Liu, J.; Galan, J.E. High-resolution view of the type III secretion export apparatus in situ reveals membrane remodeling and a secretion pathway. Proc. Natl. Acad. Sci. USA 2019, 116, 24786-24795. [CrossRef]

26. Ogino, T.; Ohno, R.; Sekiya, K.; Kuwae, A.; Matsuzawa, T.; Nonaka, T.; Fukuda, H.; Imajoh-Ohmi, S.; Abe, A. Assembly of the type III secretion apparatus of enteropathogenic Escherichia coli. J. Bacteriol. 2006, 188, 2801-2811. [CrossRef]

27. Sekiya, K.; Ohishi, M.; Ogino, T.; Tamano, K.; Sasakawa, C.; Abe, A. Supermolecular structure of the enteropathogenic Escherichia coli type III secretion system and its direct interaction with the EspA-sheath-like structure. Proc. Natl. Acad. Sci. USA 2001, 98, 11638-11643. [CrossRef]

28. Ide, T.; Laarmann, S.; Greune, L.; Schillers, H.; Oberleithner, H.; Schmidt, M.A. Characterization of translocation pores inserted into plasma membranes by type III-secreted Esp proteins of enteropathogenic Escherichia coli. Cell. Microbiol. 2001, 3, 669-679. [CrossRef]

29. Chatterjee, A.; Caballero-Franco, C.; Bakker, D.; Totten, S.; Jardim, A. pore-forming activity of the Escherichia coli type III secretion system protein EspD. J. Biol. Chem. 2015, 290, 25579-25594. [CrossRef]

30. Thomas, N.A.; Deng, W.; Puente, J.L.; Frey, E.A.; Yip, C.K.; Strynadka, N.C.; Finlay, B.B. CesT is a multi-effector chaperone and recruitment factor required for the efficient type III secretion of both LEE- and non-LEE-encoded effectors of enteropathogenic Escherichia coli. Mol. Microbiol. 2005, 57, 1762-1779. [CrossRef] 
31. Takaya, A.; Takeda, H.; Tashiro, S.; Kawashima, H.; Yamamoto, T. Chaperone-mediated secretion switching from early to middle substrates in the type III secretion system encoded by Salmonella pathogenicity island 2. J. Biol. Chem. 2019, 294, $3783-3793$. [CrossRef]

32. Serapio-Palacios, A.; Finlay, B.B. Dynamics of expression, secretion and translocation of type III effectors during enteropathogenic Escherichia coli infection. Curr. Opin. Microbiol. 2020, 54, 67-76. [CrossRef]

33. Diepold, A. Assembly and Post-assembly Turnover and Dynamics in the Type III Secretion System. Curr. Top. Microbiol. Immunol. 2020, 427, 35-66. [CrossRef]

34. Portaliou, A.G.; Tsolis, K.C.; Loos, M.S.; Zorzini, V.; Economou, A. Type III Secretion: Building and Operating a Remarkable Nanomachine. Trends Biochem. Sci. 2016, 41, 175-189. [CrossRef]

35. Monjaras Feria, J.; Garcia-Gomez, E.; Espinosa, N.; Minamino, T.; Namba, K.; Gonzalez-Pedrajo, B. Role of EscP (Orf16) in injectisome biogenesis and regulation of type III protein secretion in enteropathogenic Escherichia coli. J. Bacteriol. 2012, 194, 6029-6045. [CrossRef]

36. Deng, W.; Li, Y.; Hardwidge, P.R.; Frey, E.A.; Pfuetzner, R.A.; Lee, S.; Gruenheid, S.; Strynakda, N.C.; Puente, J.L.; Finlay, B.B. Regulation of type III secretion hierarchy of translocators and effectors in attaching and effacing bacterial pathogens. Infect. Immun. 2005, 73, 2135-2146. [CrossRef]

37. Armentrout, E.I.; Rietsch, A. The Type III Secretion Translocation Pore Senses Host Cell Contact. PLoS Pathog. 2016, 12, e1005530. [CrossRef]

38. Torruellas, J.; Jackson, M.W.; Pennock, J.W.; Plano, G.V. The Yersinia pestis type III secretion needle plays a role in the regulation of Yop secretion. Mol. Microbiol. 2005, 57, 1719-1733. [CrossRef]

39. Martinez-Argudo, I.; Blocker, A.J. The Shigella T3SS needle transmits a signal for MxiC release, which controls secretion of effectors. Mol. Microbiol. 2010, 78, 1365-1378. [CrossRef]

40. Roehrich, A.D.; Guillossou, E.; Blocker, A.J.; Martinez-Argudo, I. Shigella IpaD has a dual role: Signal transduction from the type III secretion system needle tip and intracellular secretion regulation. Mol. Microbiol. 2013, 87, 690-706. [CrossRef]

41. Kubori, T.; Galan, J.E. Salmonella type III secretion-associated protein InvE controls translocation of effector proteins into host cells. J. Bacteriol. 2002, 184, 4699-4708. [CrossRef]

42. Liu, L.Y.; Nie, P.; Yu, H.B.; Xie, H.X. Regulation of Type III Secretion of Translocon and Effector Proteins by the EsaB/EsaL/EsaM Complex in Edwardsiella tarda. Infect. Immun. 2017, 85. [CrossRef]

43. Ferracci, F.; Schubot, F.D.; Waugh, D.S.; Plano, G.V. Selection and characterization of Yersinia pestis YopN mutants that constitutively block Yop secretion. Mol. Microbiol. 2005, 57, 970-987. [CrossRef]

44. Yang, H.; Shan, Z.; Kim, J.; Wu, W.; Lian, W.; Zeng, L.; Xing, L.; Jin, S. Regulatory role of PopN and its interacting partners in type III secretion of Pseudomonas aeruginosa. J. Bacteriol. 2007, 189, 2599-2609. [CrossRef] [PubMed]

45. Botteaux, A.; Sory, M.P.; Biskri, L.; Parsot, C.; Allaoui, A. MxiC is secreted by and controls the substrate specificity of the Shigella flexneri type III secretion apparatus. Mol. Microbiol. 2009, 71, 449-460. [CrossRef]

46. Yu, X.J.; McGourty, K.; Liu, M.; Unsworth, K.E.; Holden, D.W. pH sensing by intracellular Salmonella induces effector translocation. Science 2010, 328, 1040-1043. [CrossRef] [PubMed]

47. Tandhavanant, S.; Matsuda, S.; Hiyoshi, H.; Iida, T.; Kodama, T. Vibrio parahaemolyticus senses intracellular K(+) to translocate type III secretion system 2 effectors effectively. MBio 2018, 9. [CrossRef]

48. Portaliou, A.G.; Tsolis, K.C.; Loos, M.S.; Balabanidou, V.; Rayo, J.; Tsirigotaki, A.; Crepin, V.F.; Frankel, G.; Kalodimos, C.G.; Karamanou, S.; et al. Hierarchical protein targeting and secretion is controlled by an affinity switch in the type III secretion system of enteropathogenic Escherichia coli. EMBO J. 2017, 36, 3517-3531. [CrossRef] [PubMed]

49. Gaytan, M.O.; Monjaras Feria, J.; Soto, E.; Espinosa, N.; Benitez, J.M.; Georgellis, D.; Gonzalez-Pedrajo, B. Novel insights into the mechanism of SepL-mediated control of effector secretion in enteropathogenic Escherichia coli. Microbiologyopen 2018, 7, e00571. [CrossRef]

50. Yu, X.J.; Grabe, G.J.; Liu, M.; Mota, L.J.; Holden, D.W. SsaV Interacts with SsaL to Control the Translocon-to-Effector Switch in the Salmonella SPI-2 Type Three Secretion System. MBio 2018, 9. [CrossRef]

51. Lee, P.C.; Zmina, S.E.; Stopford, C.M.; Toska, J.; Rietsch, A. Control of type III secretion activity and substrate specificity by the cytoplasmic regulator PcrG. Proc. Natl. Acad. Sci. USA 2014, 111, 6863. [CrossRef]

52. Shen, D.K.; Blocker, A.J. MxiA, MxiC and IpaD Regulate Substrate Selection and Secretion Mode in the T3SS of Shigella flexneri. PLoS ONE 2016, 11, e0155141. [CrossRef]

53. Coombes, B.K.; Brown, N.F.; Valdez, Y.; Brumell, J.H.; Finlay, B.B. Expression and secretion of Salmonella pathogenicity island-2 virulence genes in response to acidification exhibit differential requirements of a functional type III secretion apparatus and SsaL. J. Biol. Chem. 2004, 279, 49804-49815. [CrossRef]

54. Deng, W.; Puente, J.L.; Gruenheid, S.; Li, Y.; Vallance, B.A.; Vazquez, A.; Barba, J.; Ibarra, J.A.; O'donnell, P.; Metalnikov, P.; et al. Dissecting virulence: Systematic and functional analyses of a pathogenicity island. Proc. Natl. Acad. Sci. USA 2004, 101, 3597-3602. [CrossRef]

55. Day, J.B.; Plano, G.V. A complex composed of SycN and YscB functions as a specific chaperone for YopN in Yersinia pestis. Mol. Microbiol. 1998, 30, 777-788. [CrossRef]

56. Yu, X.J.; Liu, M.; Holden, D.W. SsaM and SpiC interact and regulate secretion of Salmonella pathogenicity island 2 type III secretion system effectors and translocators. Mol. Microbiol. 2004, 54, 604-619. [CrossRef] 
57. Kresse, A.U.; Beltrametti, F.; Muller, A.; Ebel, F.; Guzman, C.A. Characterization of SepL of enterohemorrhagic Escherichia coli. J. Bacteriol. 2000, 182, 6490-6498. [CrossRef]

58. O'Connell, C.B.; Creasey, E.A.; Knutton, S.; Elliott, S.; Crowther, L.J.; Luo, W.; Albert, M.J.; Kaper, J.B.; Frankel, G.; Donnenberg, M.S. SepL, a protein required for enteropathogenic Escherichia coli type III translocation, interacts with secretion component SepD. Mol. Microbiol. 2004, 52, 1613-1625. [CrossRef]

59. Younis, R.; Bingle, L.E.; Rollauer, S.; Munera, D.; Busby, S.J.; Johnson, S.; Deane, J.E.; Lea, S.M.; Frankel, G.; Pallen, M.J. SepL resembles an aberrant effector in binding to a class 1 type III secretion chaperone and carrying an $\mathrm{N}$-terminal secretion signal. J. Bacteriol. 2010, 192, 6093-6098. [CrossRef]

60. Tsai, N.P.; Wu, Y.C.; Chen, J.W.; Wu, C.F.; Tzeng, C.M.; Syu, W.J. Multiple functions of 10036 in the regulation of the pathogenicity island of enterohaemorrhagic Escherichia coli O157:H7. Biochem. J. 2006, 393, 591-599. [CrossRef]

61. Shaulov, L.; Gershberg, J.; Deng, W.; Finlay, B.B.; Sal-Man, N. The Ruler Protein EscP of the Enteropathogenic Escherichia coli Type III Secretion System Is Involved in Calcium Sensing and Secretion Hierarchy Regulation by Interacting with the Gatekeeper Protein SepL. MBio 2017, 8. [CrossRef] [PubMed]

62. Dmitrova, M.; Younes-Cauet, G.; Oertel-Buchheit, P.; Porte, D.; Schnarr, M.; Granger-Schnarr, M. A new LexA-based genetic system for monitoring and analyzing protein heterodimerization in Escherichia coli. Mol. Gen. Genet. 1998, 257, 205-212. [CrossRef] [PubMed]

63. Levine, M.M.; Bergquist, E.J.; Nalin, D.R.; Waterman, D.H.; Hornick, R.B.; Young, C.R.; Sotman, S. Escherichia coli strains that cause diarrhoea but do not produce heat-labile or heat-stable enterotoxins and are non-invasive. Lancet 1978, 1, 1119-1122. [CrossRef]

64. Gauthier, A.; Puente, J.L.; Finlay, B.B. Secretin of the enteropathogenic Escherichia coli type III secretion system requires components of the type III apparatus for assembly and localization. Infect. Immun. 2003, 71, 3310-3319. [CrossRef]

65. Ohnishi, K.; Ohto, Y.; Aizawa, S.; Macnab, R.M.; Iino, T. FlgD is a scaffolding protein needed for flagellar hook assembly in Salmonella typhimurium. J. Bacteriol. 1994, 176, 2272-2281. [CrossRef]

66. Ryu, J.; Hartin, R.J. Quick transformation in Salmonella typhimurium LT2. Biotechniques 1990, 8, $43-45$.

67. McDonald, P.N. Two-hybrid systems. Methods and protocols. Introduction. Methods Mol. Biol. 2001, 177, v-viii.

68. Datsenko, K.A.; Wanner, B.L. One-step inactivation of chromosomal genes in Escherichia coli K-12 using PCR products. Proc. Natl. Acad. Sci. USA 2000, 97, 6640-6645. [CrossRef]

69. Uzzau, S.; Figueroa-Bossi, N.; Rubino, S.; Bossi, L. Epitope tagging of chromosomal genes in Salmonella. Proc. Natl. Acad. Sci. USA 2001, 98, 15264-15269. [CrossRef]

70. Hoang, T.T.; Karkhoff-Schweizer, R.R.; Kutchma, A.J.; Schweizer, H.P. A broad-host-range Flp-FRT recombination system for site-specific excision of chromosomally-located DNA sequences: Application for isolation of unmarked Pseudomonas aeruginosa mutants. Gene 1998, 212, 77-86. [CrossRef]

71. Ohnishi, K.; Fan, F.; Schoenhals, G.J.; Kihara, M.; Macnab, R.M. The FliO, FliP, FliQ, and FliR proteins of Salmonella typhimurium: Putative components for flagellar assembly. J. Bacteriol. 1997, 179, 6092-6099. [CrossRef]

72. Gonzalez-Pedrajo, B.; Minamino, T.; Kihara, M.; Namba, K. Interactions between C ring proteins and export apparatus components: A possible mechanism for facilitating type III protein export. Mol. Microbiol. 2006, 60, 984-998. [CrossRef]

73. Tsai, S.P.; Hartin, R.J.; Ryu, J. Transformation in restriction-deficient Salmonella typhimurium LT2. J. Gen. Microbiol. 1989, 135, 2561-2567. [CrossRef]

74. Miller, J.H. Experiments in Molecular Genetics; Cold Spring Harbor Lab. Press: Cold Spring Harbor, NY, USA, $1972 ;$ p. 466.

75. Peterson, G.L. A simplification of the protein assay method of Lowry et al. which is more generally applicable. Anal. Biochem. 1977, 83, 346-356. [CrossRef]

76. Yang, J.; Yan, R.; Roy, A.; Xu, D.; Poisson, J.; Zhang, Y. The I-TASSER Suite: Protein structure and function prediction. Nat Methods 2015, 12, 7-8. [CrossRef]

77. Schubot, F.D.; Jackson, M.W.; Penrose, K.J.; Cherry, S.; Tropea, J.E.; Plano, G.V.; Waugh, D.S. Three-dimensional structure of a macromolecular assembly that regulates type III secretion in Yersinia pestis. J. Mol. Biol. 2005, 346, 1147-1161. [CrossRef]

78. Pettersen, E.F.; Goddard, T.D.; Huang, C.C.; Couch, G.S.; Greenblatt, D.M.; Meng, E.C.; Ferrin, T.E. UCSF Chimera-A visualization system for exploratory research and analysis. J. Comput. Chem. 2004, 25, 1605-1612. [CrossRef]

79. Heo, L.; Park, H.; Seok, C. GalaxyRefine: Protein structure refinement driven by side-chain repacking. Nucleic Acids Res. 2013, 41, W384-W388. [CrossRef]

80. Lupas, A. Coiled coils: New structures and new functions. Trends Biochem. Sci. 1996, 21, 375-382. [CrossRef]

81. Bustamante, V.H.; Santana, F.J.; Calva, E.; Puente, J.L. Transcriptional regulation of type III secretion genes in enteropathogenic Escherichia coli: Ler antagonizes H-NS-dependent repression. Mol. Microbiol. 2001, 39, 664-678. [CrossRef]

82. Elliott, S.J.; Hutcheson, S.W.; Dubois, M.S.; Mellies, J.L.; Wainwright, L.A.; Batchelor, M.; Frankel, G.; Knutton, S.; Kaper, J.B. Identification of CesT, a chaperone for the type III secretion of Tir in enteropathogenic Escherichia coli. Mol. Microbiol. 1999, 33, 1176-1189. [CrossRef]

83. Abe, A.; de Grado, M.; Pfuetzner, R.A.; Sanchez-Sanmartin, C.; Devinney, R.; Puente, J.L.; Strynadka, N.C.; Finlay, B.B. Enteropathogenic Escherichia coli translocated intimin receptor, Tir, requires a specific chaperone for stable secretion. Mol. Microbiol. 1999, 33, 1162-1175. [CrossRef] [PubMed]

84. Burkinshaw, B.J.; Souza, S.A.; Strynadka, N.C. Structural analysis of SepL, an enteropathogenic Escherichia coli type III secretionsystem gatekeeper protein. Acta Crystallogr. Sect. F Struct. Biol. Commun. 2015, 71, 1300-1308. [CrossRef] 
85. Zarivach, R.; Deng, W.; Vuckovic, M.; Felise, H.B.; Nguyen, H.V.; Miller, S.I.; Finlay, B.B.; Strynadka, N.C. Structural analysis of the essential self-cleaving type III secretion proteins EscU and SpaS. Nature 2008, 453, 124-127. [CrossRef] [PubMed]

86. Thomassin, J.L.; He, X.; Thomas, N.A. Role of EscU auto-cleavage in promoting type III effector translocation into host cells by enteropathogenic Escherichia coli. BMC Microbiol. 2011, 11, 205. [CrossRef]

87. Wagner, S.; Grin, I.; Malmsheimer, S.; Singh, N.; Torres-Vargas, C.E.; Westerhausen, S. Bacterial type III secretion systems: A complex device for the delivery of bacterial effector proteins into eukaryotic host cells. FEMS Microbiol. Lett. 2018, 365. [CrossRef] [PubMed]

88. Elbaz, N.; Socol, Y.; Katsowich, N.; Rosenshine, I. Control of Type III Secretion System Effector/Chaperone Ratio Fosters Pathogen Adaptation to Host-Adherent Lifestyle. MBio 2019, 10. [CrossRef] [PubMed]

89. Silva-Herzog, E.; Joseph, S.S.; Avery, A.K.; Coba, J.A.; Wolf, K.; Fields, K.A.; Plano, G.V. Scc1 (CP0432) and Scc4 (CP0033) function as a type III secretion chaperone for CopN of Chlamydia pneumoniae. J. Bacteriol. 2011, 193, 3490-3496. [CrossRef] [PubMed]

90. Gazi, A.D.; Charova, S.N.; Panopoulos, N.J.; Kokkinidis, M. Coiled-coils in type III secretion systems: Structural flexibility, disorder and biological implications. Cell. Microbiol. 2009, 11, 719-729. [CrossRef]

91. Wang, D.; Roe, A.J.; McAteer, S.; Shipston, M.J.; Gally, D.L. Hierarchal type III secretion of translocators and effectors from Escherichia coli O157:H7 requires the carboxy terminus of SepL that binds to Tir. Mol. Microbiol. 2008, 69, 1499-1512. [CrossRef]

92. Monjaras Feria, J.V.; Lefebre, M.D.; Stierhof, Y.D.; Galan, J.E.; Wagner, S. Role of autocleavage in the function of a type III secretion specificity switch protein in Salmonella enterica serovar Typhimurium. MBio 2015, 6. [CrossRef]

93. Zilkenat, S.; Franz-Wachtel, M.; Stierhof, Y.D.; Galan, J.E.; Macek, B.; Wagner, S. Determination of the Stoichiometry of the Complete Bacterial Type III Secretion Needle Complex Using a Combined Quantitative Proteomic Approach. Mol. Cell. Proteomics 2016, 15, 1598-1609. [CrossRef]

94. Terahara, N.; Inoue, Y.; Kodera, N.; Morimoto, Y.V.; Uchihashi, T.; Imada, K.; Ando, T.; Namba, K.; Minamino, T. Insight into structural remodeling of the FlhA ring responsible for bacterial flagellar type III protein export. Science Adv. 2018, 4, eaao7054. [CrossRef]

95. Inoue, Y.; Ogawa, Y.; Kinoshita, M.; Terahara, N.; Shimada, M.; Kodera, N.; Ando, T.; Namba, K.; Kitao, A.; Imada, K.; et al. Structural Insights into the Substrate Specificity Switch Mechanism of the Type III Protein Export Apparatus. Structure 2019, 27, 965-976. [CrossRef]

96. Minamino, T.; Inoue, Y.; Kinoshita, M.; Namba, K. FliK-Driven Conformational Rearrangements of FlhA and FlhB Are Required for Export Switching of the Flagellar Protein Export Apparatus. J. Bacteriol. 2020, 202. [CrossRef]

97. Ngo, T.D.; Perdu, C.; Jneid, B.; Ragno, M.; Novion Ducassou, J.; Kraut, A.; Coute, Y.; Stopford, C.; Attree, I.; Rietsch, A.; et al. The PopN Gate-keeper Complex Acts on the ATPase PscN to Regulate the T3SS Secretion Switch from Early to Middle Substrates in Pseudomonas aeruginosa. J. Mol. Biol. 2020, 432, 166690. [CrossRef]

98. Ruano-Gallego, D.; Alvarez, B.; Fernandez, L.A. Engineering the Controlled Assembly of Filamentous Injectisomes in E. coli K-12 for Protein Translocation into Mammalian Cells. ACS Synth. Biol. 2015, 4, 1030-1041. [CrossRef] 